\title{
COMPUTATIONAL METHOD AND NUMERICAL SIMULATION OF TEMPERATURE FIELD FOR LARGE-SPACE STEEL STRUCTURES IN FIRE
}

\author{
Sheng-gang Fan ${ }^{1, *}$, Gan-Ping Shu ${ }^{1}$, Guang-Jun She ${ }^{2}$, J.Y. Richard Liew ${ }^{3}$ \\ ${ }^{1}$ School of Civil Engineering, Key Laboratory of Concrete and Prestressed Structures of Ministry of Education \\ Southeast University, Nanjing, 210096, China \\ ${ }^{2}$ Nanjing Architectural Design and Research Institute Co., Ltd., Nanjing, 210000, China \\ ${ }^{3}$ Department of Civil engineering, National University of Singapore, Singapore, 117576, Singapore \\ *(Corresponding author: E-mail: 101010393@seu.edu.cn)
}

Received: 16 October 2012; Revised: 2 February 2013; Accepted: 16 December 2013

\begin{abstract}
For large-space steel structures in fire, an accurate temperature field model is essential to predict the temperature distribution for response analysis of the structure. Based on the field model theories of air thermodynamics and heat transfer, the combustion process and temperature distribution of large-space steel structures in fire were analyzed in this paper. The temperature field model of large-space fire, including fire source, smoke plume and smoke layers models, was established. Closed form formulas were developed to predict the air temperature, within its application limit, near the ceiling of large-space steel structures in fire. The accuracy of the formulas was verified by comparing with results obtained from numerical method based on field models. This research provides an important theoretical basis for further studying the behavior of large-space steel structures in fire.
\end{abstract}

Keywords: Large-space steel structures, fire, temperature field, computational method, numerical simulation, thermodynamics, heat transfer

\section{INTRODUCTION}

Structures would be affected by fire, through energy transferred from uncontrolled combustion process. In large space fire, structures are firstly affected by heat from convection and radiation, and then the rise of structural temperature leads to additional thermal stresses due to boundary constraints and sharp decline of structural stiffness and strength. Under the influence of these combined actions and effect of materials in high temperature, structural damage or collapse may occur. One of the most significant preconditions of the whole process of analysis and design of large-space steel structures in fire is to establish an accurate temperature field model in fire to predict the temperature distribution in large structure.

Nowadays, researches on temperature field model are mostly focused on indoor small space fire, while studies on large space fire are not enough. Large space fire have many different attributes and features compared to indoor small space fire such as huge volume, higher space height, full combustion, faster air flow rate, larger heat distribution gradient, obvious local effects, and further distance from structural elements to fire source (Fan et al. [1]; Yu et al. [2]). Therefore, there may be great differences in the temperature field model for large and small space fire. Based on research findings by Li and Du [3], Xue et al. [4], Cooper [5] and Venkatasubbaiah and Jaluria [6], there are four available methods to establish air temperature field model in fire:

(1) The standard ISO834 fire, which is mainly suitable for indoor small space or compartment fire.

(2) Live fire test measuring method, which is mainly applicable to indoor large space fire. However, the testing is very rather costly, and the restricted test parameters often limit their applications.

(3) Analysis method based on zone models, which tend to be more accurate for fire at the initial fire development stage. However as the fire develops into a more mature stage, calculation deviation tends to accumulate leading less accurate prediction of temperature field. 
(4)Numerical simulation method based on field models, which can accurately predict, in time and space, air temperature rise in a large space fire. This method may provide reliable analysis of temperature rise in structural members, and is applicable of capturing the entire process of combustion for the purpose of structural analysis at elevated temperature.

On the basis of theories on combustion, fluids and heat transfer, the motion of hot smoke and heat transfer of fire were analyzed in this paper, and the laws in combustion process were revealed. In addition, a mathematical model of air temperature field in large space fire was built. Finally, closed form formulas to predict the air temperature near the ceiling of large-space steel structures in fire was proposed.

\section{COMBUSTION CHARACTERISTICS OF LARGE SPACE FIRE}

A large space fire mainly undergoes four phases of combustion: initial growth, full development, stable burning and decay, among which the full development phase is the most important one as it has a profound influence on the temperature distribution and response of structure in large space fire. In this phase, as fire continues and flame height constantly increases, the hot air mixed with carbon black produced during combustion continually rises under the action of buoyancy, and forms a cylindrical smoke plume, as displayed in Figure 1. For large space fire which shows tendency towards stabilization, its temperature field model mainly includes models of fire source, smoke plume, and smoke layer.

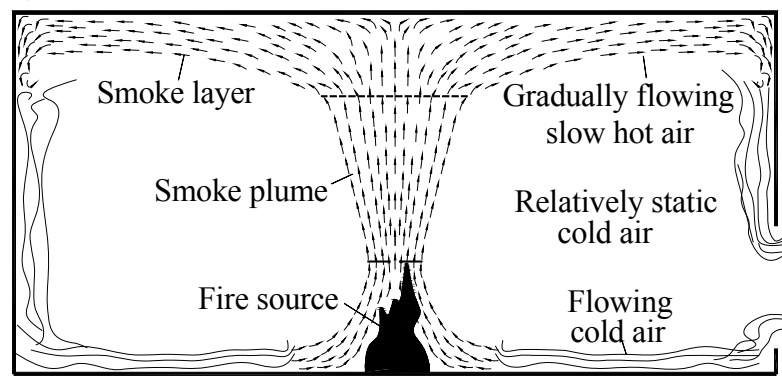

Figure 1. Sketch of Full Development Phase of Large Space Fire

\subsection{Combustion Characteristics of Fire Source}

Fire source is the only energy source in combustion process, and it exchanges heat with the air primarily by means of convection and radiation. The total heat amount released from fire source is the decisive factor of the temperature field.

The radiation heat generally comes from carbon black produced during combustion. In the initial phase of combustion, there is only 10 percent of the total heat released from fire source, because of relatively low indoor temperature. However, as temperature rises, and a large number of carbon black has been produced, the maximum radiation heat can reach about $15 \% \sim 20 \%$ of the total heat amount (Floyd et al. [7]; Chow and Yin [8]). In this paper, the radiation heat is taken as $20 \%$ of the total heat, and the convective heat is regarded as $80 \%$ of the total heat. Assuming the total heat amount released from fire source is $Q$, the convective heat and radiation heat will be $Q_{\mathrm{c}}$ and $Q_{\mathrm{e}}$ respectively, and then it is obvious that $Q=Q_{\mathrm{c}}+Q_{\mathrm{e}}$, and $Q_{\mathrm{c}}=0.8 Q$.

\subsection{Temperature Distribution of the Smoke Plume}

As smoke plume rises, its volume expands by entraining surrounding cold air, pushing the boundary layer outwards, as shown in Figure 2. Assuming that the indoor air is isotropic and the 
fire source is axisymmetric, the smoke plume will be similar to an inverted axisymmetric cone. The temperature distribution of smoke plume can be described as follows: (1) the highest temperature always locate in the centre whatever the cross section, and it decreases gradually to the lowest (approximately equals to room temperature) in the boundary layer, as displayed in Figure 2 (a), and (2) along the vertical direction, the centreline temperature falls down gradually with the height increasing, as shown in Figure 2 (b).

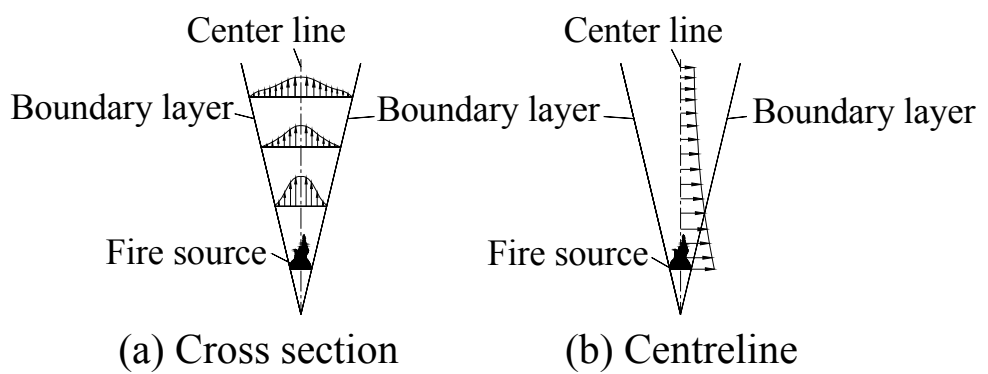

Figure 2. Air Temperature Distribution of Smoke Plume

In the process of combustion, the relevant parameters of smoke plume, such as flow rate, temperature, and the density distribution, can be accurately simulated through fluid theory. The precondition of forming a stable smoke plume in large space fire is that the ceiling has a certain height. For large-space steel structures, if the height of ceiling exceeds $10 \mathrm{~m}$ an obvious smoke plume will be developed ( $\mathrm{Li}$ and $\mathrm{Du}$ [9]; Huang and Wen [10]).

\subsection{Temperature Distribution of Smoke Layer}

After the rising smoke plume collides with the ceiling of a large-space steel structure, an impact area is firstly formed, as illustrated in Figure 3. Additionally, the smoke plume moves horizontally to two sides, and the smoke layer is formed. The smoke layer contains most of the convective heat released from the fire source. Therefore, for large-space steel structures, the temperature of structure and components are influenced by temperature distribution of the smoke layer directly. It is important to capture the temperature distribution of this smoke layer for the analysis of structural fire resistance.

The temperature distribution law in smoke layer can be described as follow (Shi et al. [11]; Cooper and Stroup [12-13]):

(1) The temperature declines step by step from the centreline of impact area to surrounding areas. The impact area exhibits great air temperature gradient along horizontal direction, and obvious local effects.

(2) As burning continues, the smoke layer accumulates more heat and increases its thickness gradually.

(3) For thickness direction of the smoke layer, the temperature falls down gradually as the height decreases, until it meets the indoor temperature.

(4) With heat release rate declining, the increment of temperature and thickness gradually drops, and the smoke layer comes to be stable.

Figure 3 illustrates the temperature distribution of the smoke layer at the ceiling of large-space steel structures. 




\section{TEMPERATURE FIELD MODEL OF LARGE SPACE FIRE}

\subsection{Model of Fire Source}

The fire source model is defined as the relationship between the heat release rate and the burning time. The crucial parameters include the fire load density, the burning rate of the fire source, the maximum heat release rate, the burning area, the flame height, and the burning time. However, the complex combustion process with great randomness in variety, mass, and distribution of the combustibles, makes it difficult to determine the fire source model, and parameters precisely. Nowadays, the method combines mathematical statistics with experimental research is widely adopted by researchers in this field.

\subsubsection{Fire load density}

Fire load density $q_{\mathrm{F}}$ is defined as the heat released by the fire source per unit burning area per unit time, which depends on the variety, mass and distribution of the combustibles. Relevant statistical analysis of fire date by Harmathy [14], Anon [15], and Vrouwenvelder [16) revealed that there is a great difference in the value of fire load density for various building functions, such as residence, office, and school, in different countries.

Sunil and Kameswara [17] prescribed that the fire load density could be taken as $q_{\mathrm{F}}=500 \mathrm{~kJ} / \mathrm{m}^{2}$ for malls and other public places, as well as warehouses of supermarkets. The large space structures studied in this paper are public buildings for commercial use, so the fire load density is chosen as $q_{\mathrm{F}}=500 \mathrm{~kJ} / \mathrm{m}^{2}$.

\subsubsection{Burning rate of the fire source}

The burning rate of the fire source reveals the relationship between heat release rate of the fire source and burning time, which depends on the variety of combustibles and the indoor ventilation conditions. Considering large space fire, the heat release rate of the fire source is basically proportional to the square of burning time (Harmathy and Mehaffey [18]), expressed by

$Q(t)=\left\{\begin{array}{lr}\alpha t^{2} & 0<t \leq t_{\mathrm{p}} \\ Q_{\max } & t>t_{\mathrm{p}}\end{array}\right.$

where $Q(t)$ is the heat release rate of the fire source at a certain time (MW), $Q_{\max }$ is the maximum heat release rate of the fire source (MW), $\alpha$ is the increasing coefficient of the heat 
release rate $\left(\mathrm{kW} / \mathrm{s}^{2}\right)$, which is determined according to the fire growth rate in Table 1 , and $\mathrm{t}$ is the burning time (s); $t_{\mathrm{p}}=\sqrt{Q_{\max } / \alpha}$ is the time of the heat release rate reaching the maximum value(s).

Table 1. Increasing Coefficient of Heat Release Rate $\alpha\left(\mathrm{kW} / \mathrm{s}^{2}\right)$

\begin{tabular}{|c|c|c|c|c|}
\hline $\begin{array}{c}\text { Burning rate of the fire } \\
\text { source }\end{array}$ & Slow & Medium & Fast & Very fast \\
\hline Coefficient $\alpha$ & 0.002931 & 0.011270 & 0.046890 & 0.187800 \\
\hline
\end{tabular}

\subsubsection{Maximum heat release rate}

The maximum heat release rate $Q_{\max }$ is influenced by the variety of combustibles, the building function, and the fire-fighting facilities. In this paper, based on the research findings from She [19], the values of $Q_{\max }$ are taken as $5 \mathrm{MW}, 10 \mathrm{MW}, 15 \mathrm{MW}, 20 \mathrm{MW}$, e and $25 \mathrm{MW}$ respectively which corresponding to different building enclosures as illustrated in Table 2.

Table 2. Maximum Heat Release Rate for Different Building Enclosures

\begin{tabular}{|c|c|c|l|}
\hline $\begin{array}{c}\text { Values of } \\
Q_{\max }\end{array}$ & Fire severity & $\begin{array}{c}\text { Fire-fighting } \\
\text { facility }\end{array}$ & \multicolumn{1}{c|}{ Building Enclosures } \\
\hline $5 \mathrm{MW}$ & Mild & $\begin{array}{c}\text { With } \\
\text { sprinkler }\end{array}$ & $\begin{array}{l}\text { Waiting room, gymnasium and other public } \\
\text { buildings }\end{array}$ \\
\hline $10 \mathrm{MW}$ & Medium & No sprinkler & $\begin{array}{l}\text { Waiting room, gymnasium and other public } \\
\text { buildings }\end{array}$ \\
\hline $15 \mathrm{MW}$ & Relatively severe & $\begin{array}{l}\text { With } \\
\text { sprinkler }\end{array}$ & $\begin{array}{l}\text { Shopping malls, supermarkets, warehouses, } \\
\text { libraries and other large space buildings }\end{array}$ \\
\hline $20 \mathrm{MW}$ & Severe & No sprinkler & $\begin{array}{l}\text { Shopping malls, supermarkets, warehouses, } \\
\text { libraries and other large space buildings }\end{array}$ \\
\hline $25 \mathrm{MW}$ & Extremely severe & - & $\begin{array}{l}\text { large-space steel structures that contain a large } \\
\text { number of flammable and explosive chemicals }\end{array}$ \\
\hline
\end{tabular}

\subsubsection{Burning area and flame height}

The spread of the burning surface is affected by many factors with certain randomness. In order to simplify the calculation, it is assumed that the boundary of the fire source in large space fire advances to all directions at the same rate, and the burning surface has the same heat release rate. Therefore, the shape of the fire source model can be regarded as an axisymmetric cone [20], which is shown in Figure 4. The burning area and the flame height per unit time can be obtained as

$$
A=\pi(D / 2)^{2}=Q(t) t / q_{\mathrm{F}} \quad ; \quad L=0.235 Q(t)^{2 / 5}-1.02 D
$$

where $A$ is the burning area of the fire source per unit time $\left(\mathrm{m}^{2}\right)$; $\mathrm{D}$ is the diameter at the bottom of the fire source model per unit time $(\mathrm{m}) ; L$ is the flame height per unit time $(\mathrm{m}) ; \mathrm{t}$ represents the burning time, which is taken as $1 \mathrm{~s}$. 


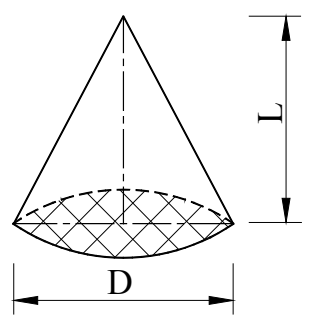

Figure 4. Simplified Model of the Fire Source

When the maximum heat release rate is reached, for example, $Q(t)=Q_{\max }, A$ and $L$ for different fire scenarios can be obtained from Eq. 2.

\subsubsection{Burning duration}

The burning duration $t_{\mathrm{m}}$ is defined as the total time taken from the initiation of the fire to its natural extinguishment, as shown in Figure 5 (a).

Based on the principle of energy conservation, the total amount of heat released from the fire source should be equal to the integral of the heat release rate $Q(t)$ throughout the burning duration, which is demonstrated as the shaded area in Figure 5 (a). In order to simplify calculation, the descending curve in the extinguishing phase may be approximated by an equivalent vertical line according to the conservation of the total heat, as shown in Figure 5 (b).

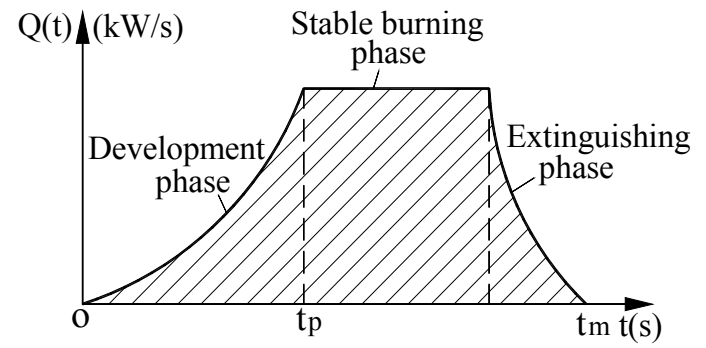

(a) Actual model

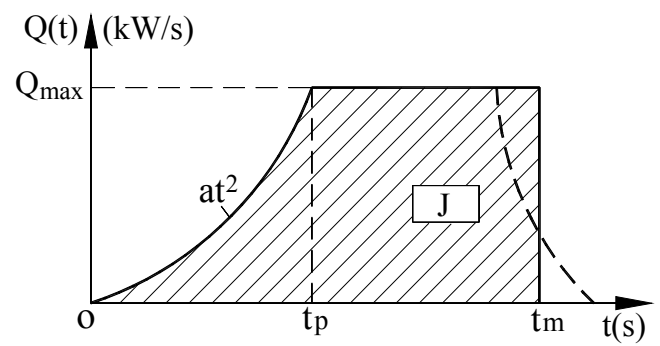

(b) Simplified model

Figure 5. The Relationship between Heat and Duration of Fire

From Figure 5 (b), the total amount of heat $J$ released from the fire source can be derived by solving the integral of Eq. 3.

$$
J=q_{F} A=\int_{0}^{t_{\mathrm{m}}} Q(t) \mathrm{d} t=\int_{0}^{t_{\mathrm{p}}} \alpha t^{2} \mathrm{~d} t+\int_{t_{\mathrm{p}}}^{t_{\mathrm{m}}} Q_{\max } \mathrm{d} t=\alpha t_{\mathrm{p}}^{3} / 3+Q_{\max }\left(t_{\mathrm{m}}-t_{\mathrm{p}}\right)
$$

in which

$$
t_{\mathrm{m}}=t_{\mathrm{p}}+\left(q_{\mathrm{F}} A-\alpha t_{\mathrm{p}}^{3} / 3\right) / Q_{\max }
$$

where $A=\sum_{\mathrm{i}}\left(m_{\mathrm{i}} q_{\mathrm{i}}\right) / q_{\mathrm{F}}$ is the equivalent area after normalizing the heat release rate of all combustibles according to $q_{\mathrm{F}} ; m_{\mathrm{i}}$ and $q_{\mathrm{i}}$ are, respectively, the total mass of the $i$ type of combustibles $(\mathrm{kg})$, and the heat release rate per unit mass $(\mathrm{kJ} / \mathrm{kg})$. 
Based on the test data from Chow et al. [21] and William [22], for large space fire the total mass of combustibles ranges from 200 to $2000 \mathrm{~kg}$ and the average heat release rate per unit mass is approximately $25 \times 10^{3} \mathrm{~kJ} / \mathrm{kg}$. In addition, corresponding to five values of $Q_{\max }=5 \mathrm{MW}, 10 \mathrm{MW}$, $15 \mathrm{MW}, 20 \mathrm{MW}$, and $25 \mathrm{MW}$, the burning duration $t_{\mathrm{m}}$ for different mass of combustibles and different fire growth rates can be calculated from Eq. 4. The calculation results are shown in Figure 6.

The results in Figure 6 demonstrate that the burning duration $t_{\mathrm{m}}$ would rarely exceed 80 minutes (see curves of FS-10, VS-25 and so on), if the total mass of combustibles is lower than $2000 \mathrm{~kg}$. Only when the value of $Q_{\max }$ is $5 \mathrm{MW}$, and the mass of combustibles exceeds $1400 \mathrm{~kg}$, the burning duration $t_{\mathrm{m}}$ can reach and even more than 120 minutes (see curves of SS-5, MS-5, FS-5, and VS-5). Therefore, it is proposed that the burning duration of large space fire can be taken conservatively as $t_{\mathrm{m}}=120 \mathrm{~min}$.

\subsection{Model of Smoke Plume}

The smoke plume model mainly depends on the distribution in time and space of flow rate, density, temperature, and other state parameters of the smoke, as shown in Figures 7 (a) to (c). According to previous discussion, the shape of the smoke plume is similar to an inverted axisymmetric cone, and thus its motion equation can be derived with the cylindrical coordinates system. The rising direction and the radial direction of smoke plume are assumed as the $\mathrm{z}$ and $\mathrm{r}$ axis respectively, and the corresponding flow rates to two axes are $u$ and $v$ separately. Based on the principles of mass conservation (the continuity equation), momentum conservation (the motion equation), and energy conservation (the energy equation) of the smoke plume, the differential equations of smoke plume are obtained as follows (Motevalli [23]; Zukoski et al. [24]).

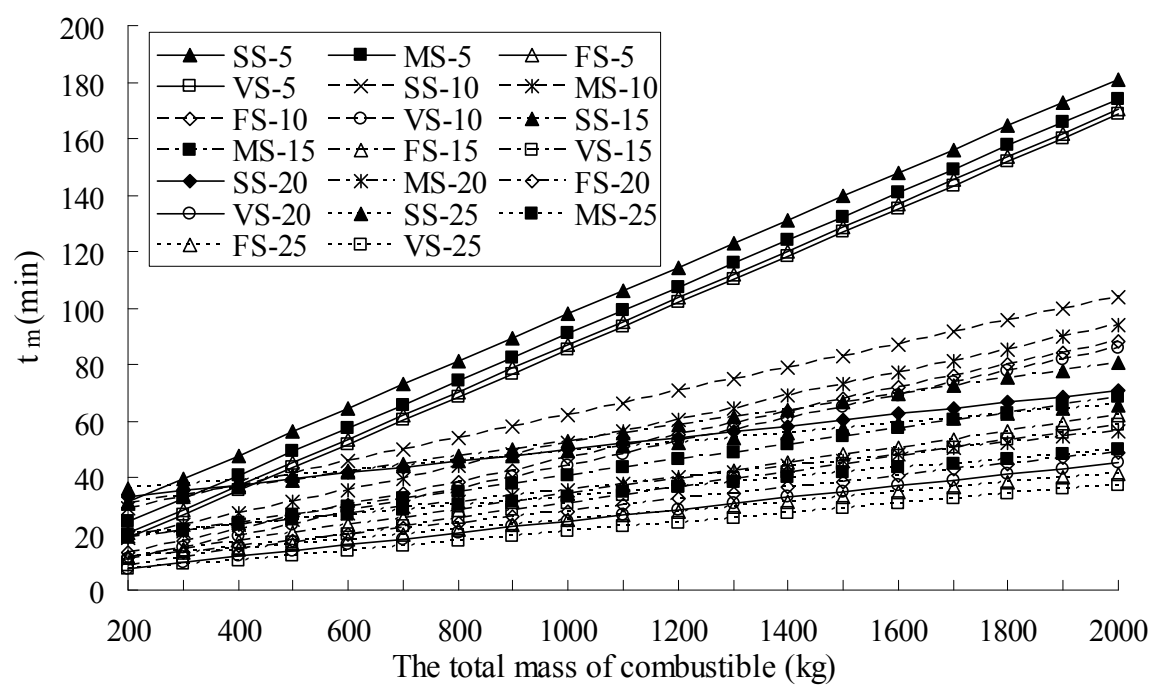

Figure 6. The Burning Duration of Fire $t_{\mathrm{m}}$

(SS represents slow, MS represents the medium, FS represents fast, VS represents very fast, as shown in Table 1) 


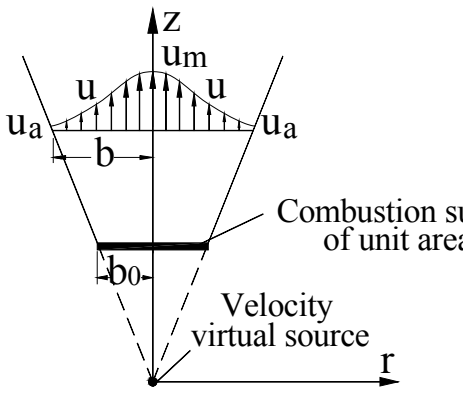

(a) Flow rate distribution

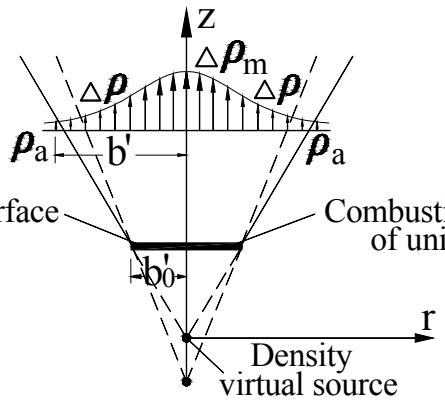

(b) Density distribution

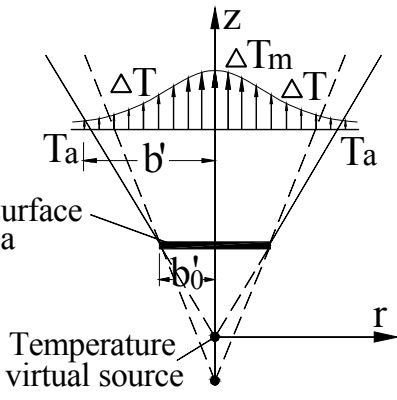

(c) Temperature distribution

Figure 7. Actual Distribution of State Parameters

Continuity equation:

$$
\partial u / \partial z+\partial v / \partial r+v / r=0
$$

Motion equation:

$$
u \frac{\partial u}{\partial z}+v \frac{\partial v}{\partial r}=-g-\frac{1}{\rho} \frac{\partial p}{\partial z}-\frac{1}{r} \frac{\partial}{\partial r}(r \overline{u v})
$$

Energy equation:

$$
u \frac{\partial \Delta T}{\partial z}+v \frac{\partial \Delta T}{\partial r}=-\frac{1}{r} \frac{\partial}{\partial r}(r \overline{u \Delta T}), u \frac{\partial \Delta \rho}{\partial z}+v \frac{\partial \Delta \rho}{\partial r}=-\frac{1}{r} \frac{\partial}{\partial r}(r \overline{u \Delta \rho})
$$

where $\Delta T=T_{\mathrm{a}}-T, \Delta \rho=\rho_{\mathrm{a}}-\rho$.

Considering a unit volume of the smoke along the symmetry axis, the differential equations are solved with boundary conditions and assumptions. The air temperature $T_{\mathrm{m}}$ along the centreline of the smoke plume can be expressed as (Gershuni et al. [25]):

$$
T_{\mathrm{m}}=T_{\mathrm{a}}+11.21 \times V_{0}^{2 / 3}\left[\left(\rho_{\mathrm{a}}-\rho_{0}\right) g / \rho_{\mathrm{a}}\right]^{-1 / 3} z^{-5 / 3}\left(T_{0}-T_{\mathrm{a}}\right)
$$

where $T_{\mathrm{m}}$ is the air temperature at the point where the vertical distance along the centreline is $\mathrm{z}$ from the fire source $\left({ }^{\circ} \mathrm{C}\right) ; T_{0}$ is the air temperature of the burning surface $\left({ }^{\circ} \mathrm{C}\right) ; T_{a}$ is the indoor temperature $\left({ }^{\circ} \mathrm{C}\right) ; \rho_{\mathrm{a}}$ and $\rho_{0}$ are, respectively, the density of the surrounding air, and the initial density of the burning surface $\left(\mathrm{kg} / \mathrm{m}^{3}\right) ; g$ is the acceleration of gravity $\left(\mathrm{m} / \mathrm{s}^{2}\right) ; V_{0}$ is the volume flux across a certain cross section of the smoke plume.

Assuming that the heat release rate on the burning surface is evenly distributed, the rising velocity, density, and temperature of the surrounding air would also approximately follow uniform distribution, as demonstrated in Figures 8(a) to (c). Ignoring the influence of the sudden change of the parameters around the circumference of the burning surface, the following formula can be obtained.

$$
\mathrm{Q}_{\mathrm{c}}=\mathrm{q} \Delta \mathrm{t}=\mathrm{c}_{\mathrm{p}} \mathrm{m}_{0}\left(\mathrm{~T}_{0}-\mathrm{T}_{\mathrm{a}}\right)
$$

where $Q_{c}$ is the convective heat release rate of the fire source; $\Delta t$ is the time duration of the heating process; $c_{\mathrm{p}}$ is the coefficient of the specific heat at constant pressure for air; $m_{0}$ is the mass of the heated air, and $q$ is the heat release rate of the fire source per unit area. 


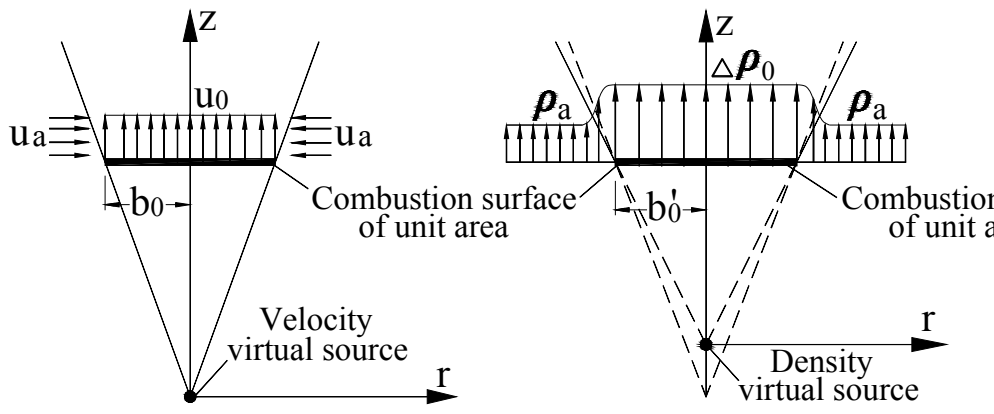

(a) Velocity distribution (b) Density distribution

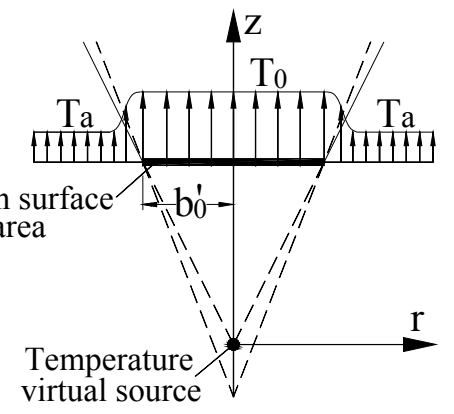

(c) Temperature distribution

Figure 8. Simplified Distribution of State Parameters

It can be obtained from Figure 8(a) that $m_{0}=\pi b_{0}^{2} u_{0} \Delta t \rho_{0}, V_{0}=\pi b_{0}^{2} u_{0}$. Introducing them into Eq. 7, the following relationship can be obtained:

$$
q=c_{\mathrm{p}} \pi b_{0}^{2} u_{0} \rho_{0}\left(T_{0}-T_{\mathrm{a}}\right) \quad, \quad V_{0}=q / c_{\mathrm{p}} \rho_{0}\left(T_{0}-T_{\mathrm{a}}\right)
$$

Introducing Eq. 8 into Eq. 6, the following formula can be derived.

$T_{\mathrm{m}}=T_{\mathrm{a}}+11.21 \times\left[\frac{\rho_{\mathrm{a}}\left(T_{0}-T_{\mathrm{a}}\right)}{g c_{\mathrm{p}}^{2} \rho_{0}^{2}\left(\rho_{\mathrm{a}}-\rho_{0}\right)}\right]^{1 / 3} q^{2 / 3} z^{-5 / 3}$

Introducing a virtual temperature source, which is demonstrated in Figure 9, the burning area can be extended from a unit area to the whole surface. Therefore, replacing the heat release rate per unit area $\mathrm{q}$ with the total heat release rate $Q_{\mathrm{c}}$ in Eq. 9 , the air temperature can be expressed as:

$T_{\mathrm{m}}=T_{\mathrm{a}}+11.21 \times\left[\frac{\rho_{\mathrm{a}}\left(T_{0}-T_{\mathrm{a}}\right)}{g c_{\mathrm{p}}^{2} \rho_{0}^{2}\left(\rho_{\mathrm{a}}-\rho_{0}\right)}\right]^{1 / 3} Q_{\mathrm{c}}^{2 / 3}\left(z+z_{0}\right)^{-5 / 3}$

where $z_{0}$ is the vertical distance between the virtual temperature source and the fire source. Using Eq. 10 and $T_{\mathrm{m}}=T_{0}$, the position of the virtual temperature source is expressed by

$z_{0}=4.26 \times\left[\frac{\rho_{\mathrm{a}} Q_{\mathrm{c}}{ }^{2}}{g c_{\mathrm{p}}^{2} \rho_{0}^{2}\left(\rho_{\mathrm{a}}-\rho_{0}\right)\left(T_{0}-T_{\mathrm{a}}\right)^{2}}\right]^{1 / 5}$

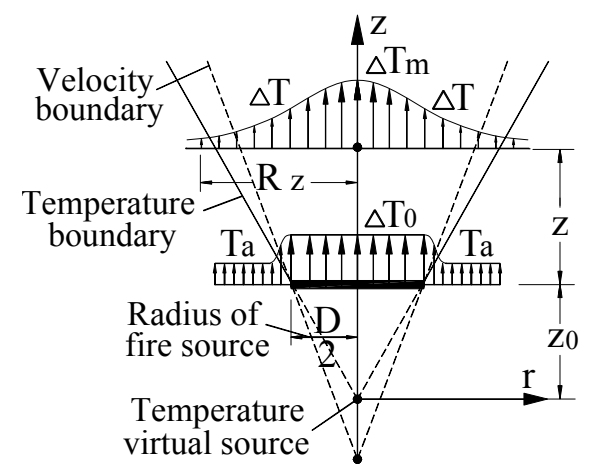

Figure 9. Distribution of Temperature in the Smoke Plume 
According to the parameter changes with temperature of thermal physical properties of air at normal pressure, and the burning test results of different combustibles (Guan[26]), the flame temperature of most fibrous combustibles is $1200^{\circ} \mathrm{C}$. Therefore introducing $T_{0}=1200^{\circ} \mathrm{C}$, $\rho_{0}=0.2322 \mathrm{~kg} / \mathrm{m}^{3}, \quad \rho_{\mathrm{a}}=1.1614 \mathrm{~kg} / \mathrm{m}^{3}, \quad C_{\mathrm{p}}=1.230 \mathrm{~kJ} / \mathrm{m}^{3}, \quad T_{\mathrm{a}}=23^{\circ} \mathrm{C}, \quad g=9.8 \mathrm{~m} / \mathrm{s}^{2}, \quad$ and $Q_{c}=0.8 Q$ into Eq. 10 and 11, the following formulas can be obtained.

$$
\begin{aligned}
& T_{\mathrm{m}}=T_{\mathrm{a}}+119.15 \times Q^{2 / 3}\left(z+z_{0}\right)^{-5 / 3} \\
& Z_{0}=0.25 Q^{2 / 5}
\end{aligned}
$$

Based on the similarity principle of the smoke plume model (Fang et al. [27]), the distribution of temperature difference can be described as follow.

$$
\Delta T / \Delta T_{\mathrm{m}}=\left(T_{\mathrm{r}}-T_{\mathrm{a}}\right) /\left(T_{\mathrm{m}}-T_{\mathrm{a}}\right)=\exp \left[-\operatorname{Pr}(r / b)^{2}\right]
$$

where $T_{\mathrm{r}}$ is the air temperature of the smoke plume $\left({ }^{\circ} \mathrm{C}\right) ; \operatorname{Pr}$ is the Prandtl number of air, which may be taken as 0.72 according to Guan [26]; $b$ is the half width of the temperature field at the position where the vertical distance is $\mathrm{z}$ from the fire source, $b=0.102 \times\left(z+z_{0}\right)$. Introducing Eq. 12a into Eq. 13 yields:

$$
T_{\mathrm{r}}=T_{\mathrm{a}}+\exp \left[-67.28 \times r^{2} /\left(z+z_{0}\right)^{2}\right]\left[119.15 \times Q_{\mathrm{c}}^{2 / 3}\left(z+z_{0}\right)^{-5 / 3}\right]
$$

By varying the total heat release rate $Q_{\mathrm{c}}$ as $5 \mathrm{MW}, 10 \mathrm{MW}, 15 \mathrm{MW}, 20 \mathrm{MW}$, and $25 \mathrm{MW}$, and the vertical height $\mathrm{z}$ from 0 to $20 \mathrm{~m}$, air temperature of the smoke plume $T_{\mathrm{m}}$ along the centreline of the fire source can be obtained from Eq. 12a and Eq. 12b and they are plotted in Figure 10. Figure 11 plots the results of the radical temperature profile of the smoke plume using Eq. 14.

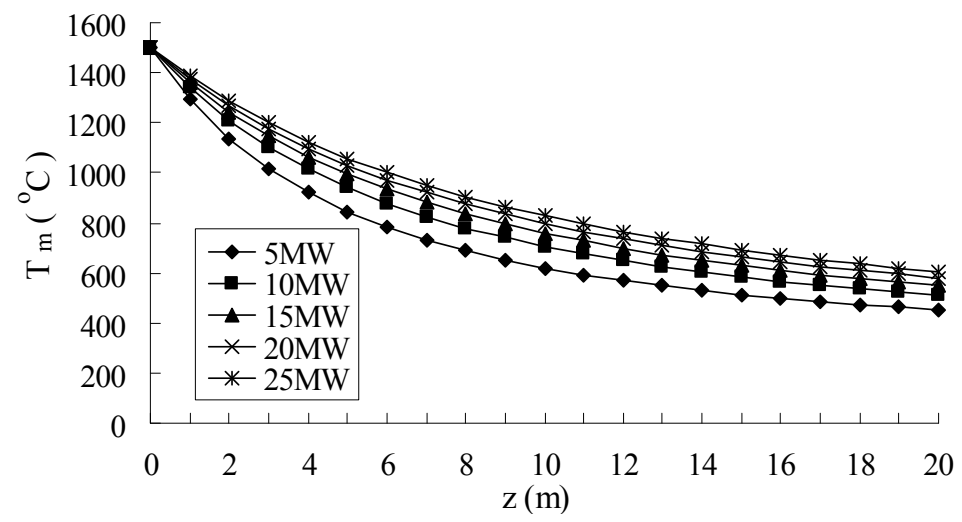

Figure 10. $T_{\mathrm{m}}-z$ Curves of Smoke Plume along the Centreline of Fire Source 




Figure 11. $T_{\mathrm{r}}-r$ Curves of Smoke Plume at Different Heights for $Q_{\mathrm{c}}=20 \mathrm{MW}$

According to Eq. 15a and Eq. 15b, the maximum centreline flow rate of the hot air $u_{\mathrm{m}}$ can be solved.

$v_{\mathrm{n}}^{2}-v_{\mathrm{n}-1}^{2}=2 a_{\mathrm{m}} \Delta h$

$v_{\mathrm{n}}=v_{\mathrm{n}-1}+a_{\mathrm{m}} \Delta t$

where $v_{\mathrm{n}}$ and $v_{\mathrm{n}-1}$ is the flow rates of air at different heights of the smoke plume; $\alpha_{\mathrm{m}}$ is the rising acceleration of the smoke plume; $\Delta h$ and $\Delta t$ are, respectively, the height step, and the time step for iteration.

Considering the value of total heat release rate $Q_{\mathrm{c}}$ as $5 \mathrm{MW}, 10 \mathrm{MW}, 15 \mathrm{MW}, 20 \mathrm{MW}$, and $25 \mathrm{MW}$ respectively, and the vertical height $\mathrm{z}$ ranges from 0 to $20 \mathrm{~m}$, based on Eq. $15 \mathrm{a}$ and Eq. 15b, the maximum centreline flow rate $u_{\mathrm{m}}$ of the hot air in the smoke plume can be solved with iteration method, as displayed in Figure 12.

The curves in Figure 12 demonstrate that $u_{\mathrm{m}}$ is basically in linear relationship with the logarithm of height $z$. With data fitting, as displayed in Figure 12, the maximum flow rate $u_{\mathrm{m}}$ can be expressed as follows.

$u_{\mathrm{m}}=C_{1} \ln z+C_{2}$

where $C_{1}$ and $C_{2}$ are the fitting coefficients, their values are demonstrated in Table 3 .

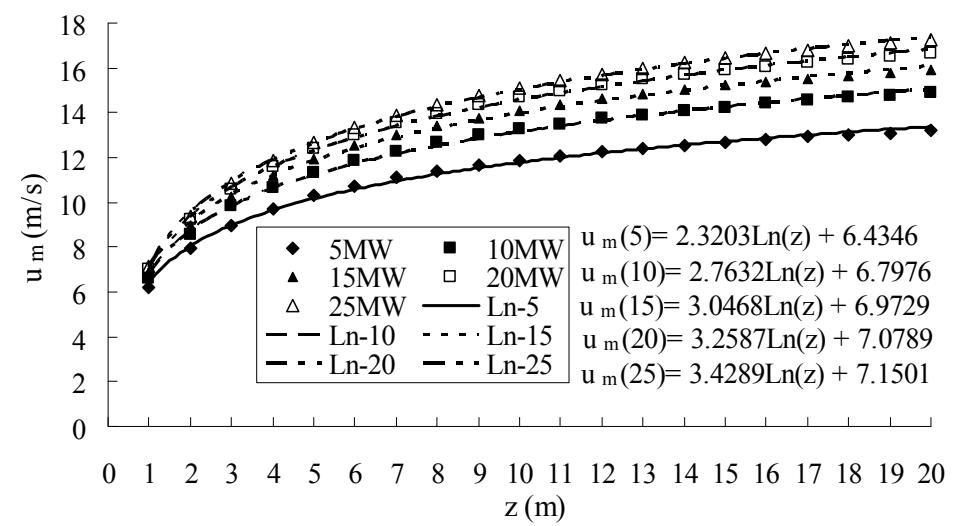

Figure 12. $u_{\mathrm{m}}-\mathrm{z}$ Curves (Where $\mathrm{Ln}$ is the Fitting Curves) 
Table3. The Value of $C_{1}$ and $C_{2}$

\begin{tabular}{|c|c|c|c|c|c|}
\hline Total heat release rate $Q_{\mathrm{c}}$ & $5 \mathrm{MW}$ & $10 \mathrm{MW}$ & $15 \mathrm{MW}$ & $20 \mathrm{MW}$ & $25 \mathrm{MW}$ \\
\hline Coefficient $C_{1}$ & 2.3203 & 2.7632 & 3.0468 & 3.2587 & 3.4289 \\
\hline Coefficient $C_{2}$ & 6.4346 & 6.7976 & 6.9729 & 7.0789 & 7.1501 \\
\hline
\end{tabular}

Based on the similarity principle of the smoke plume model (Harmathy and Mehaffey [18]), the following formula can be obtained.

$u / u_{\mathrm{m}}=\exp \left[-(r / b)^{2}\right]$

where $u$ represents the air flow rate of the smoke plume at a certain time.

Introducing Eq. 16 into Eq. 17, solving the integral, the relationship between $\bar{u}$ and $u_{\mathrm{m}}$ along the centreline can be expressed as

$\bar{u}=\frac{1}{\pi b^{2}} \int_{0}^{2 \pi} \int_{0}^{b} u_{\mathrm{m}} \exp \left(-r^{2} / b^{2}\right) r \mathrm{~d} \theta \mathrm{d} r=\left(1-e^{-1}\right) u_{\mathrm{m}}=\left(1-e^{-1}\right)\left(C_{1} \ln z+C_{2}\right)$

\subsection{Model of Smoke Layer}

In large space fire, the hot air flow is primarily divided into three areas: the smoke plume area, the impact area, and the ceiling jet area, which are demonstrated in Figure 13. In area A, the flow characteristics and the temperature distribution are detailed in section 3.2. In area B, the motion direction of the smoke plume changes significantly, which creates certain pressure gradients. The smoke in the top of this area flows nearly parallel to the ceiling. In area $\mathrm{C}$, the hot smoke continually diffuses to surrounding areas from the centreline of the fire source as the circle centre.

\subsubsection{Air temperature distribution of impact area}

The temperature, flow rate, density, and pressure of the hot smoke change significantly in the impact area. According to the test results of inverted axisymmetric smoke layer in large space fire from Beltao and Rajaratnam [28], the range of the impact area in large space fire is about $0.86 H \leq z \leq H$, in which $H$ is the distance between the burning surface and the ceiling, as shown in Figure 1.

According to Figure 14, assuming a micro unit of the hot smoke along the centreline, the pressure difference $\Delta p$ between the upper and lower surfaces in the impact area can be derived as:

$\Delta p=p_{\mathrm{s}}-p_{\mathrm{a}}=0.2\left(\rho_{\mathrm{a}}-\rho\right) g H+0.5 \rho u_{0}^{2}$

where $p_{\mathrm{s}}$ is the pressure at the stagnation point in the impact area; $p_{\mathrm{a}}$ is the pressure at the bottom of the impact area; $\rho_{\mathrm{a}}$ is the indoor air density; $\rho_{0}$ is the air density at the bottom of the impact area; $u_{0}$ is the maximum centreline flow rate of the hot air at the bottom of the impact area. 


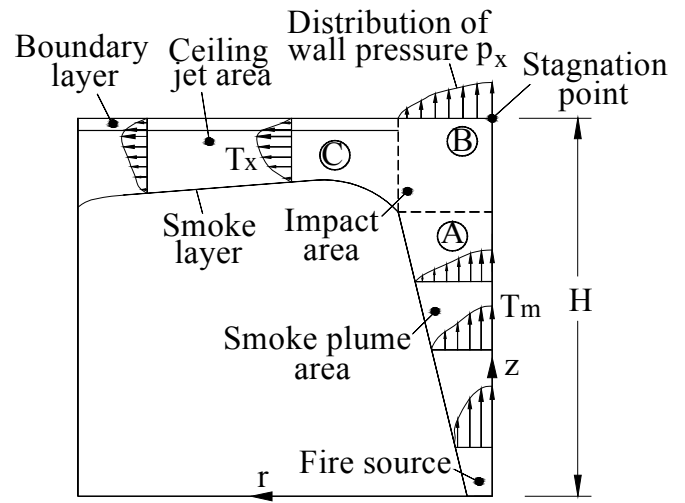

Figure 13. Partition of Smoke Layer

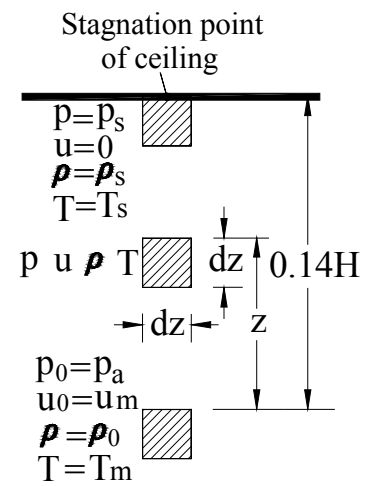

Figure 14. Micro Unit of Hot Smoke

According to the parameter changes with temperature of thermal physical properties of air (Guan [26]), it can be fitted that $\rho \approx 356 / T_{0.86 \mathrm{H}}$. Using formula (12a), (12b), and (16), $T_{0.86 \mathrm{H}}, z_{0}, u_{0}$, and $\rho$ can be obtained. Substituting these into Eq. 19, the curves of the pressure difference $\Delta p$ for different heat release rates $Q_{c}$ can be obtained, as shown in Figure 15.

In the impact area, because the hot air entrains little cold air, its density barely changes, and the temperature is approximately proportional to the pressure. $\Delta p-z$ Curves in Figure 15 point out that the pressure difference $\Delta p$ of the hot air at the stagnation point is below $100 \mathrm{~N} / \mathrm{m}^{2}$, and the relative value $\Delta p / p_{\mathrm{a}}=100 /\left(1.0 \times 10^{5}\right)=0.1 \%$ is small. Therefore the influence of the pressure on the temperature is not significant. According to Eq. 12a, the air temperature at the stagnation point near the ceiling can be expressed by relationship.

$$
T_{H}=T_{0.86 H}=T_{\mathrm{a}}+119.15 \times Q_{\mathrm{c}}^{2 / 3}\left(0.86 H+z_{0}\right)^{-5 / 3}
$$

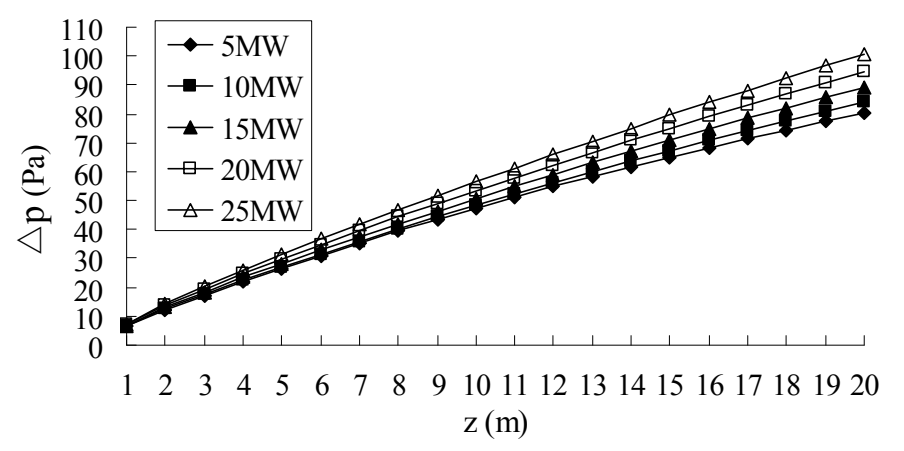

Figure 15. $\Delta p-z$ Curves for Different Values of $Q_{c}$

According to the test results from (Beltao and Rajaratnam [28], the air pressure near stagnation point can be approximately described by:

$\Delta p / \Delta p_{\mathrm{s}}=\exp \left[-0.693(r / b)^{2}\right]$

Because of the proportional relationship of air temperature with pressure in the impact area, the temperature distribution near the stagnation point can be expressed as:

$$
\left(T_{\mathrm{r}}-T_{\mathrm{a}}\right) /\left(T_{\mathrm{H}}-T_{\mathrm{a}}\right)=\exp \left[-0.693(r / b)^{2}\right]
$$


Introducing Eq. 20 into Eq. 22, the air temperature in the impact area can be obtained as

$$
T_{\mathrm{r}}=T_{\mathrm{a}}+\exp \left[-0.693(r / b)^{2}\right] \times 119.15 \times Q_{\mathrm{c}}^{2 / 3}\left(0.86 H+z_{0}\right)^{-5 / 3}
$$

where $r$ is the horizontal distance from a certain point near the ceiling to the centreline of the fire source; $b=D\left(z+z_{0}\right) / 2 z_{0}$ is the half width of the temperature field in the impact area; $D$ is the diameter of the fire source; $z_{0}$ is the vertical distance between the virtual temperature source and the fire source; $T_{\mathrm{a}}$ is the indoor temperature.

\subsubsection{Air temperature distribution of ceiling jet area}

Taking the radius of burning zone $(r=0.5 D)$ as the demarcation point of impact area and ceiling jet area, Eq. 22 takes the following form.

$$
\left(T_{\mathrm{D} / 2}-T_{\mathrm{a}}\right) /\left(T_{\mathrm{H}}-T_{\mathrm{a}}\right)=\exp \left[-0.693(0.5 D / b)^{2}\right]=\exp \left[-0.693 z_{0}^{2} /\left(z+z_{0}\right)^{2}\right]
$$

Considering the similarity principle of smoke plume model, the temperature difference in ceiling jet area can also be described as:

$$
\left(T_{\mathrm{r}}-T_{\mathrm{a}}\right) /\left(T_{\mathrm{D} / 2}-T_{\mathrm{a}}\right)=\exp \left[-\left(u_{\mathrm{m}}^{2} / u_{\mathrm{D} / 2}^{2}\right)^{1.12 P r}\right]=\exp [-(r-0.5 D) /(0.5 D)]^{2.24 P r}
$$

Letting Prandtl constant as $\operatorname{Pr} \approx 0.72$, Eq. 24 multiplied by Eq. 25 yields

$$
\left(T_{\mathrm{r}}-T_{\mathrm{a}}\right) /\left(T_{\mathrm{H}}-T_{\mathrm{a}}\right)=\exp \left[-(r-0.5 D)^{1.6} /(0.5 D)^{1.6}-0.693 z_{0}^{2} /\left(z+z_{0}\right)^{2}\right]
$$

Introducing Eq. 20 into Eq. 26, the air temperature in ceiling jet area can be obtained as

$$
T_{\mathrm{r}}-T_{\mathrm{a}}=\exp \left[-(r-0.5 D)^{1.6} /(0.5 D)^{1.6}-0.693 z_{0}^{2} /\left(z+z_{0}\right)^{2}\right] \times 119.15 \times Q_{\mathrm{c}}^{2 / 3}\left(0.86 H+z_{0}\right)^{-5 / 3} \quad r>0.5 D
$$

\subsubsection{Temperature distribution of smoke layer}

Eq. 23 may be used for calculating the air temperature in the impact area, and Eq. 27 is for calculating the air temperature in the ceiling jet area. Combining Eq. 23 with Eq. 27, the air temperature of the smoke layer in large space fire can be obtained.

$$
T_{\mathrm{r}}-T_{\mathrm{a}}= \begin{cases}\exp \left[-(r-0.5 D)^{1.6} /(0.5 D)^{1.6}-0.693 z_{0}^{2} /\left(z+z_{0}\right)^{2}\right] \times 119.15 \times Q_{\mathrm{c}}^{2 / 3}\left(0.86 H+z_{0}\right)^{-5 / 3} & r>0.5 D \\ \exp \left[-0.693 z_{0}^{2} /\left(z+z_{0}\right)^{2}\right] \times 119.15 \times Q_{\mathrm{c}}^{2 / 3}\left(0.86 H+z_{0}\right)^{-5 / 3} & r \leq 0.5 D\end{cases}
$$

Figures 16(a) and 16(b) display the air temperature distribution of the smoke layer when the value of heat release rate $Q_{\mathrm{c}}$ is $5 \mathrm{MW}$ and $20 \mathrm{MW}$ respectively. For the ceiling height $H=10 \mathrm{~m}$, and different $Q_{\mathrm{c}}$ values of 5MW, $10 \mathrm{MW}, 15 \mathrm{MW}, 20 \mathrm{MW}$, and $25 \mathrm{MW}$, the radial air temperature profile of the smoke layer is plotted as shown in Figure 17. In addition, for $H=10 \mathrm{~m}$ and $Q_{\mathrm{c}}=20 \mathrm{MW}$, the vertical air temperature profile for different distances from centreline is shown in Figure 18. 


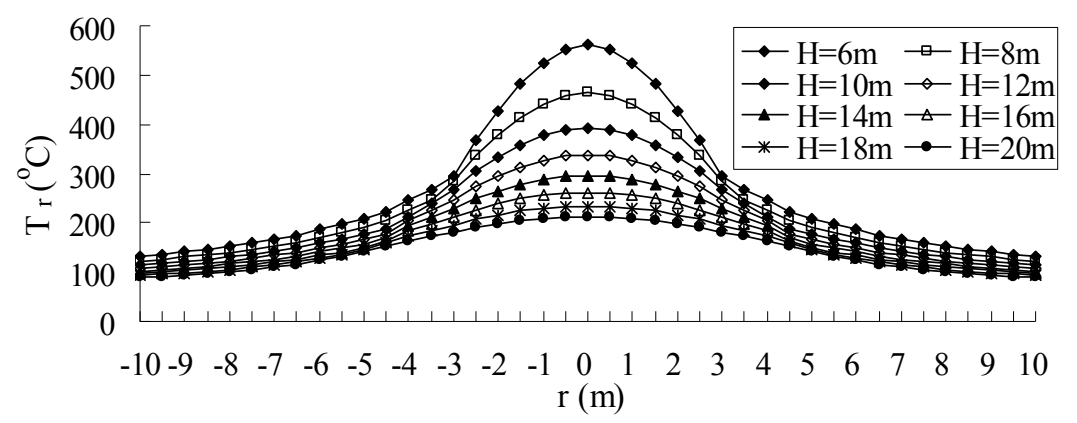

(a) $Q_{\mathrm{c}}=5 \mathrm{MW}$

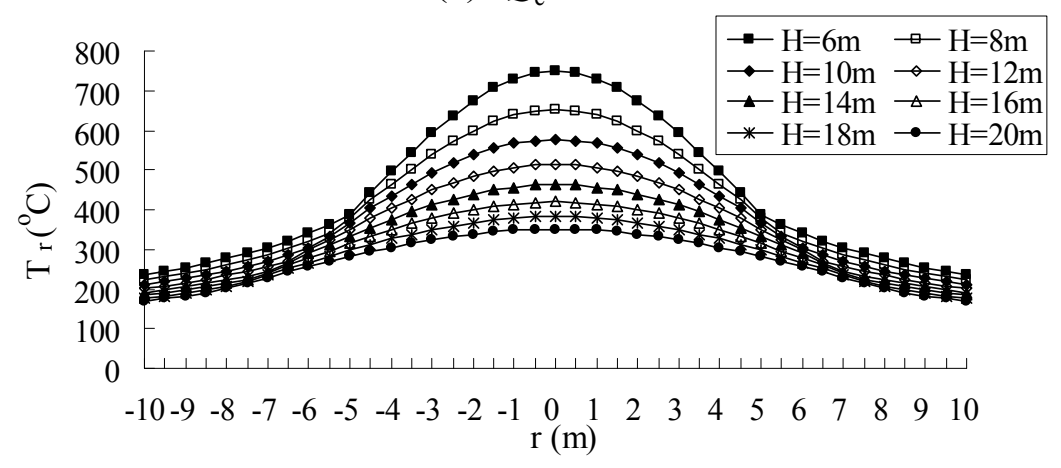

(b) $Q_{c}=20 \mathrm{MW}$

Figure 16. Radial Air Temperature Profile of Smoke Layer

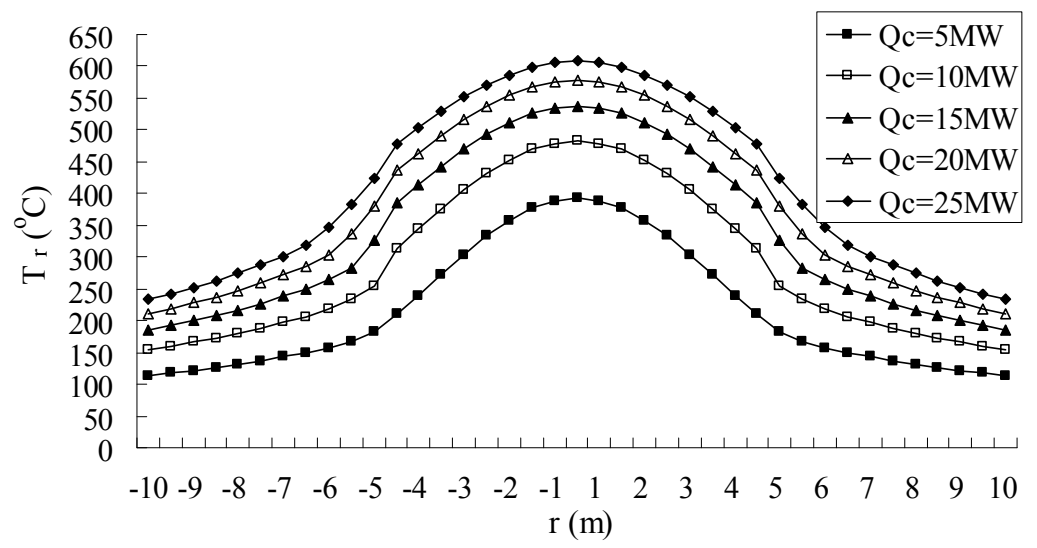

Figure 17. Radial Air Temperature Profile of Smoke Layer for Different Heat Release Rates $(H=10 \mathrm{~m})$

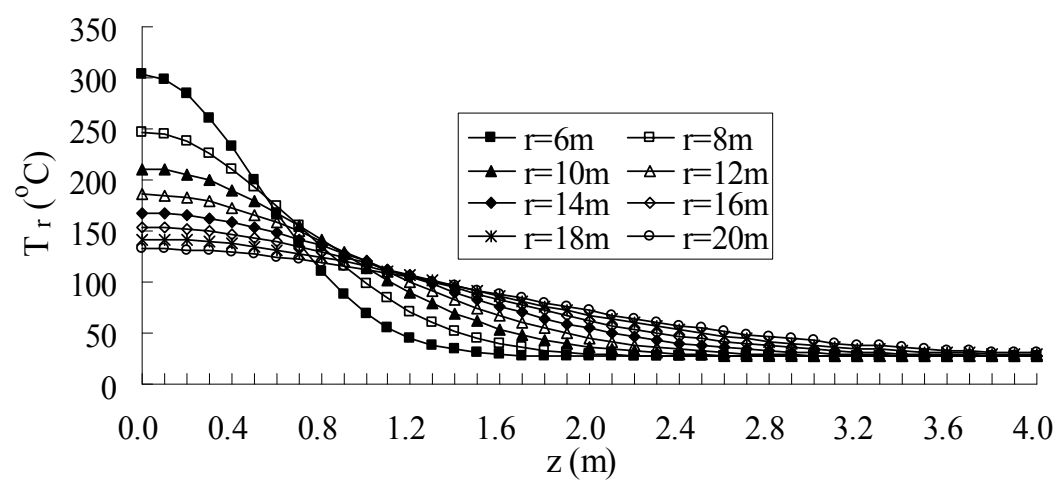

Figure 18. Vertical Air Temperature Profile of Smoke Layer at Distance $r$ from Centreline

$$
\left(H=10 \mathrm{~m}, Q_{\mathrm{c}}=20 \mathrm{MW}\right)
$$


Figure 18 shows that with the increasing time of fire, the hot smoke will accumulate in the upper space, and the smoke layer will be thicken ceaselessly.

\section{CALCULATION OF AIR TEMPERATURE NEAR THE CEILING OF LARGE SPACE}

\subsection{Modified Temperature Model in Smoke Layer}

Eq. 28 describes the air temperature distribution in the smoke layer near the ceiling of large space based on the assumption that the indoor space of large space structures is infinite. However, since most large space fire occurs in a limited space, the air temperature distribution in the smoke layer will be affected by the following three factors (Bai et al. [29]; Jin et al. [30]). (1) Limited space: since walls and other surfaces in limited space block the flow of the hot smoke, the smoke will continually accumulate near the top of the indoor space, and affect the temperature distribution. (2) Time lag: due to the large volume of the indoor space, time is needed for the rising of hot air from the fire source to the ceiling, leading to obvious time lag phenomenon in temperature field of smoke layer. (3) Temperature uniformity degree: limited by walls and other surfaces, back flow and convection of hot smoke will take place in smoke layer, in this sense, cold air and hot air mix constantly, which averages and uniformizes the air temperature near the ceiling. The influences of the three factors on the air temperature near the ceiling of large-space steel structures will be discussed in the following sections.

\subsubsection{Coefficient of limited space}

In Reference 3, the simulation software FDS of temperature field was applied to analyze a series of fire scenarios with different indoor areas, and different ceiling heights in large space. Considering the air temperature at the stagnation point near the ceiling, Table 4 shows the relevant experimental results in detail.

Table 4. Experimental Result of Air Temperature at the Stagnation Point of Ceiling

\begin{tabular}{|c|c|c|c|c|c|c|c|c|c|c|c|c|}
\hline \multirow{2}{*}{$\begin{array}{c}\text { Height of } \\
\text { eeiling } \\
\begin{array}{l}\text { Indoor } \\
\text { area } A\left(\mathrm{~m}^{2}\right)\end{array}\end{array}$} & \multicolumn{9}{|c|}{$H(\mathrm{~m})$} & \multicolumn{7}{c|}{$Q_{\mathrm{c}}=25 \mathrm{MW}$} \\
\cline { 2 - 16 } & 4 & 6 & 9 & 12 & 15 & 20 & 4 & 6 & 9 & 12 & 15 & 20 \\
\hline 500 & 603 & 573 & 573 & 573 & 553 & 463 & 1153 & 1063 & 1053 & 1053 & 1053 & 913 \\
\hline 1000 & 503 & 503 & 503 & 483 & 443 & 423 & 1103 & 973 & 933 & 903 & 883 & 853 \\
\hline 3000 & 503 & 453 & 413 & 413 & 403 & 393 & 933 & 903 & 803 & 753 & 723 & 623 \\
\hline 6000 & 433 & 413 & 393 & 383 & 373 & 353 & 833 & 813 & 753 & 683 & 653 & 613 \\
\hline
\end{tabular}

When the indoor area is $6000 \mathrm{~m}^{2}$, the indoor space is large enough to be supposed as an infinite space. Therefore, for $6000 \mathrm{~m}^{2}$ in Table 4, dividing the experimental results by those respectively, the ratio (the coefficient of limited space $\gamma_{s}$ ) of the air temperature at the stagnation point in limited space to infinite space could be obtained in detail in Table 5.

Table 5 demonstrates that the coefficient of limited space $\gamma_{s}$ mainly depends on the indoor area, the height of ceiling, and the heat release rate. For small indoor area, $\gamma_{\mathrm{s}} \rightarrow \infty$; while for infinite space, $\gamma_{\mathrm{s}} \rightarrow 1.0$. Fitting the data in Table 5, as displayed in Figures 19 (a) and (b), the coefficient of limited space $\gamma_{s}$ can be approximately expressed as: 


$$
\gamma_{\mathrm{s}}=1+Q_{\mathrm{c}}^{0.2} \exp \left(-0.1 A^{0.5} / H^{0.3}\right)
$$

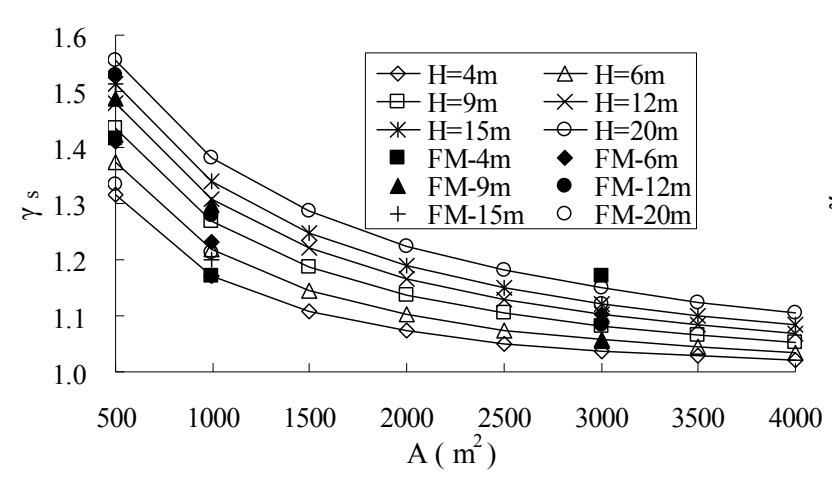

(a) $Q_{\mathrm{c}}=5 \mathrm{MW}$

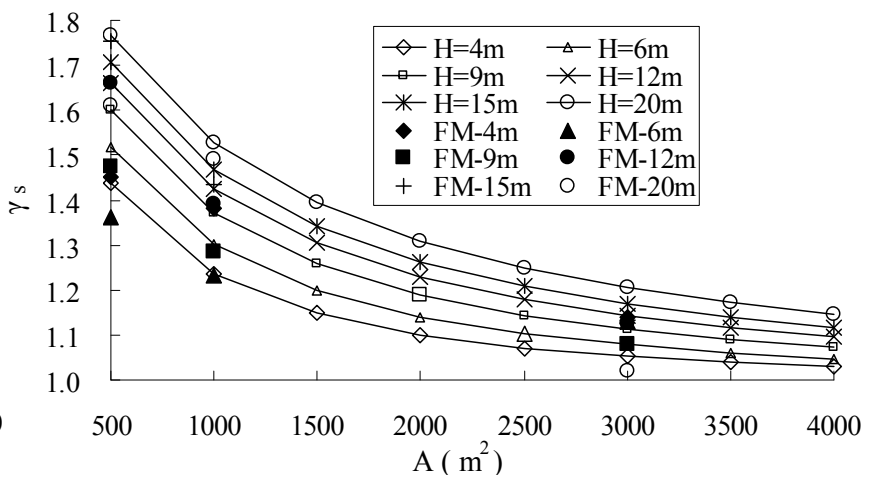

(b) $Q_{\mathrm{c}}=25 \mathrm{MW}$

Figure 19. Comparison of the Fitting Curves with Experimental Data of the Coefficient $\gamma_{\mathrm{s}}$ (FM for the Data in Table 5)

Table 5. Ratio of Air Temperature at the Stagnation Point of Ceiling in Limited Space to Infinite Space

\begin{tabular}{|c|c|c|c|c|c|c|c|c|c|c|c|c|}
\hline \multirow{3}{*}{$\begin{array}{l}\text { Height of } \\
\text { Indoor } \\
\text { Area } A\left(\mathrm{~m}^{2}\right)\end{array}$} & \multicolumn{6}{|c|}{$Q_{\mathrm{c}}=5 \mathrm{MW}$} & \multicolumn{6}{|c|}{$Q_{\mathrm{c}}=25 \mathrm{MW}$} \\
\hline & \multicolumn{6}{|c|}{$H(\mathrm{~m})$} & \multicolumn{6}{|c|}{$H(\mathrm{~m})$} \\
\hline & 4 & 6 & 9 & 12 & 15 & 20 & 4 & 6 & 9 & 12 & 15 & 20 \\
\hline 500 & 1.42 & 1.41 & 1.49 & 1.52 & 1.52 & 1.33 & 1.45 & 1.36 & 1.47 & 1.66 & 1.75 & 1.61 \\
\hline 1000 & 1.17 & 1.23 & 1.30 & 1.28 & 1.20 & 1.22 & 1.38 & 1.23 & 1.28 & 1.39 & 1.43 & 1.49 \\
\hline 3000 & 1.17 & 1.10 & 1.05 & 1.08 & 1.09 & 1.12 & 1.14 & 1.13 & 1.08 & 1.13 & 1.13 & 1.02 \\
\hline 6000 & 1.00 & 1.00 & 1.00 & 1.00 & 1.00 & 1.00 & 1.00 & 1.00 & 1.00 & 1.00 & 1.00 & 1.00 \\
\hline
\end{tabular}

The curves in Figures 19 (a) and (b) shows the relationships between the coefficient $\gamma_{s}$ with the indoor area $A$, ceiling height $H$, and heat release rate $Q_{c}$. For regular structure fire, when heat release rate $Q_{\mathrm{c}} \leq 25 \mathrm{MW}$, and indoor area is about $4000 \mathrm{~m}^{2}$, the influence of limited space on the increasing of temperature is less than $10 \%$.

\subsubsection{Coefficient of time lag}

The air temperature basically increases basically with the burning time. For large space fire, the coefficient of time $\operatorname{lag} \gamma_{t}$ is defined as the degree of the air temperature increase lagging behind the growth of heat release rate, which is expressed by the following formula ( $\mathrm{Li}$ and $\mathrm{Du}$ [3]).

$\gamma_{\mathrm{t}}=1-0.8 \exp (-\mu t)-0.2 \exp (-0.1 \mu t)$

where $t$ is the burning duration; $\mu$ is the coefficient, which depends on the fire growth rate, the maximum heat release rate, the height of ceiling, and the indoor area. As the large space fire in public structures is rapid growth type, $\mu$ takes the values in Table 6.

Table 6. The Value of Coefficient $\mu$

\begin{tabular}{|c|c|c|c|c|c|}
\hline $\begin{array}{c}\text { Maximum heat release } \\
\text { rate } Q_{\mathrm{c}}\end{array}$ & $5 \mathrm{MW}$ & $10 \mathrm{MW}$ & $15 \mathrm{MW}$ & $20 \mathrm{MW}$ & $25 \mathrm{MW}$ \\
\hline Coefficient $\mu$ & 0.0030 & 0.0024 & 0.0020 & 0.0018 & 0.0016 \\
\hline
\end{tabular}




\subsubsection{Coefficient of temperature uniformity degree}

The coefficient $\gamma_{\text {a }}$ represents the temperature uniformity degree, and $f(r)$ describes the temperature distribution of air flow near the ceiling of an infinite space. According to Eq. 28, considering the temperature uniformity degree, the air temperature near the ceiling can be described as follows.

$$
\begin{aligned}
& T_{\mathrm{r}}-T_{\mathrm{a}}=\left[\gamma_{\mathrm{a}}+\left(1-\gamma_{\mathrm{a}}\right) f(r)\right] \times 119.15 \times Q_{\mathrm{c}}^{2 / 3}\left(0.86 H+z_{0}\right)^{-5 / 3} \\
& f(r)= \begin{cases}\exp \left[-0.693(r / b)^{2}\right] & r \leq 0.5 D \\
\exp \left[-(r-0.5 D)^{1.6} /(0.5 D)^{1.6}-0.693 z_{0}^{2} /\left(z+z_{0}\right)^{2}\right] & r>0.5 D\end{cases}
\end{aligned}
$$

According to Eq. 31, for $t=0, \gamma_{\mathrm{a}}=0$; for $t \rightarrow \infty, \gamma_{\mathrm{a}}=1$.

$\mathrm{Li}$ and $\mathrm{Du}$ [3] carried out numerical simulation using FDS software for 120 cases of fire scenarios and provides the coefficient of temperature uniformity degree $\gamma_{\mathrm{a}}$ for different heat release rates, different ceiling heights, and different indoor areas, as detailed in Table 7.

According to Table 7, it can be concluded that, based on the same burning duration, larger indoor area will lead to smaller the coefficient $\gamma_{\mathrm{a}}$. Higher the ceiling leads to larger $\gamma_{\mathrm{a}}$ value; and the larger the heat release rate leads to the smaller coefficient $\gamma_{\mathrm{a}}$. In addition, among the three factors, the indoor area $A$ has the most influence on coefficient $\gamma_{a}$, and the height of ceiling $H$ has the second most influence, the heat release rate $Q_{c}$ has the least influence and hence it is ignored in this paper.

\begin{tabular}{|c|c|c|c|c|c|c|c|c|c|c|c|c|}
\hline \multirow{3}{*}{$H(\mathrm{~m})$} & \multicolumn{4}{|c|}{$Q_{\mathrm{c}}=2 \mathrm{MW}$} & \multicolumn{4}{|c|}{$Q_{\mathrm{c}}=5 \mathrm{MW}$} & \multicolumn{4}{|c|}{$Q_{\mathrm{c}}=25 \mathrm{MW}$} \\
\hline & \multicolumn{4}{|c|}{$A\left(\mathrm{~m}^{2}\right)$} & \multicolumn{4}{|c|}{$A\left(\mathrm{~m}^{2}\right)$} & \multicolumn{4}{|c|}{$A\left(\mathrm{~m}^{2}\right)$} \\
\hline & 500 & 1000 & 3000 & 6000 & 500 & 1000 & 3000 & 6000 & 500 & 1000 & 3000 & 6000 \\
\hline 4 & 0.60 & 0.40 & 0.30 & 0.15 & 0.75 & 0.60 & 0.30 & 0.20 & 0.60 & 0.40 & 0.30 & 0.20 \\
\hline 6 & 0.60 & 0.50 & 0.40 & 0.20 & 0.60 & 0.70 & 0.45 & 0.30 & 0.80 & 0.50 & 0.35 & 0.26 \\
\hline 9 & 0.65 & 0.55 & 0.45 & 0.40 & 0.75 & 0.60 & 0.60 & 0.40 & 0.55 & 0.60 & 0.50 & 0.30 \\
\hline 12 & 0.70 & 0.60 & 0.45 & 0.30 & 0.75 & 0.65 & 0.60 & 0.40 & 0.60 & 0.60 & 0.50 & 0.40 \\
\hline 15 & 0.80 & 0.70 & 0.55 & 0.40 & 0.70 & 0.75 & 0.55 & 0.45 & 0.70 & 0.60 & 0.55 & 0.40 \\
\hline 20 & 0.85 & 0.70 & 0.60 & 0.40 & 0.75 & 0.70 & 0.60 & 0.55 & 0.70 & 0.60 & 0.65 & 0.45 \\
\hline
\end{tabular}

Table 7. The Value of Coefficient $\gamma_{\mathrm{a}}$

Fitting the data in Table 7, as displayed in Figure 20, coefficient $\gamma_{\mathrm{a}}$ can be expressed as follows:

$$
\gamma_{\mathrm{a}}=1-\exp (-0.0012 t \sqrt{H / A})
$$

where $A$ is the indoor area of large space $\left(\mathrm{m}^{2}\right) ; H$ is the ceiling height (m). 


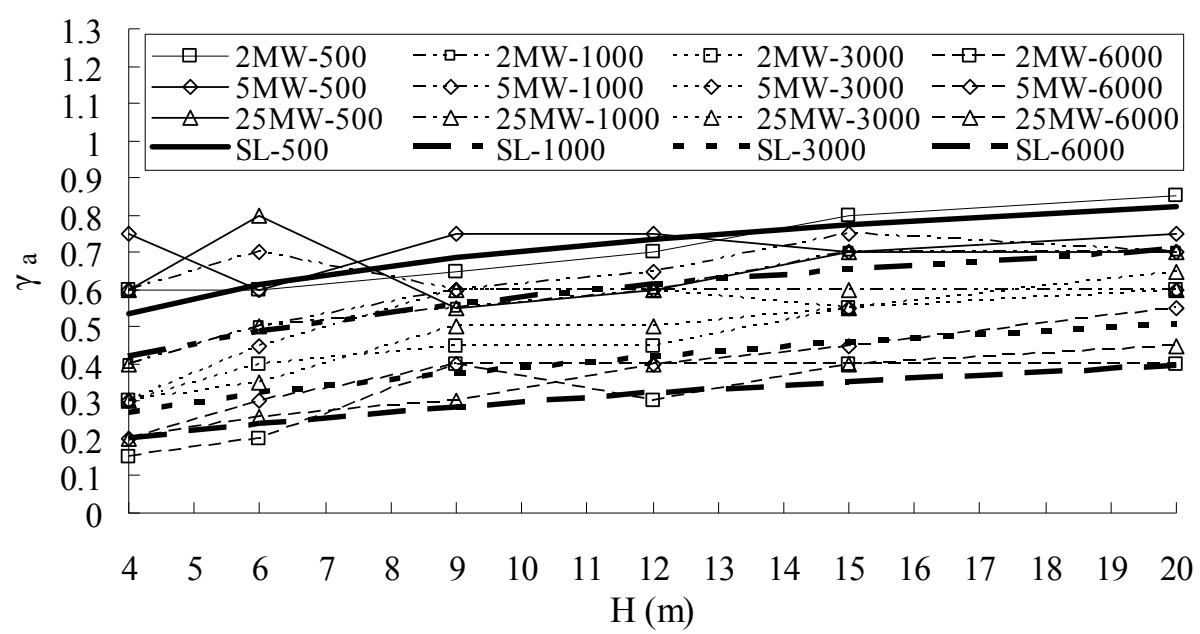

Figure 20. Comparison of the Fitting Curves with Experimental Results of the Coefficient $\gamma_{\mathrm{a}}$

(SL for the Fitting Curve)

\subsection{Prediction of Air Temperature Near the Ceiling of Large Space}

Introducing the coefficient of temperature uniformity degree $\gamma_{\mathrm{a}}$, and time lag $\gamma_{\mathrm{t}}$ into Eq. 31 , a precise formula for calculating the air temperature near the ceiling of large space can be obtained.

$T_{\mathrm{r}}-T_{\mathrm{a}}=\gamma_{\mathrm{s}} \gamma_{\mathrm{t}}\left[\gamma_{\mathrm{a}}+\left(1-\gamma_{\mathrm{a}}\right) f(r)\right]\left[119.15 \times Q_{\mathrm{c}}^{2 / 3}\left(0.86 H+0.25 Q_{\mathrm{c}}^{2 / 5}\right)^{-5 / 3}\right]$

where the coefficient $\gamma_{\mathrm{s}}, \gamma_{\mathrm{t}}, f(r)$ and $\gamma_{\mathrm{a}}$ are determined by Eq. 29, 30, 32 and 33 respectively.

\subsection{Accuracy of the Formula Proposed and Its Limitations}

$\mathrm{Li}$ and $\mathrm{Du}$ [3] recommended a formula for calculating the air temperature near the ceiling of large space structure in fire as

$T(\mathrm{x}, \mathrm{z}, \mathrm{t})-T_{\mathrm{g}}(0)=T_{\mathrm{z}}[1-0.8 \exp (-\beta t)-0.2 \exp (-0.1 \beta t)][\eta+(1-\eta) \exp (-(r-b) / \mu)]$

where $T_{\mathrm{g}}(0)$ is the initial indoor temperature; $t$ is burning duration; $r$ is the horizontal distance from the fire source; $z$ is the vertical distance from the fire source; $T_{z}, \beta, \eta, b, \mu$ are parameters depending on the fire growth type and the position of the fire source, which can be obtained from She [19].

In order to verify the accuracy of the calculation formula proposed in this paper, according to Eq. (34), and (35), the temperature is calculated respectively for different heat release rates, indoor areas, and ceiling heights. The results of comparative analysis would be discussed in this paper.

\subsection{1 $Q_{\mathrm{c}}$ is constant, changing $A$ and $H$}

Changing indoor area $A$ and ceiling height $H$, while the heat release rate $Q_{c}$ remains $25 \mathrm{MW}$, according to Eq. 34 and 35 , the air temperature distribution can be calculated respectively in Figures 21 (a) $\sim$ (d) (The temperature distribution curves of Figure 22 correspond to different burning durations--5min, 20min, 60min, and 120min). 


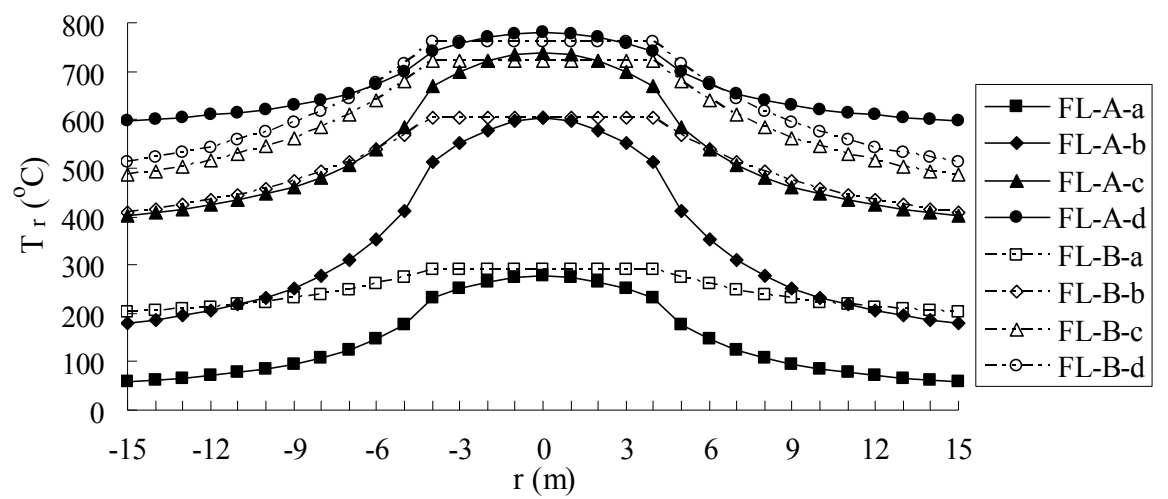

(a) $H=12 \mathrm{~m}, A=500 \mathrm{~m}^{2}$

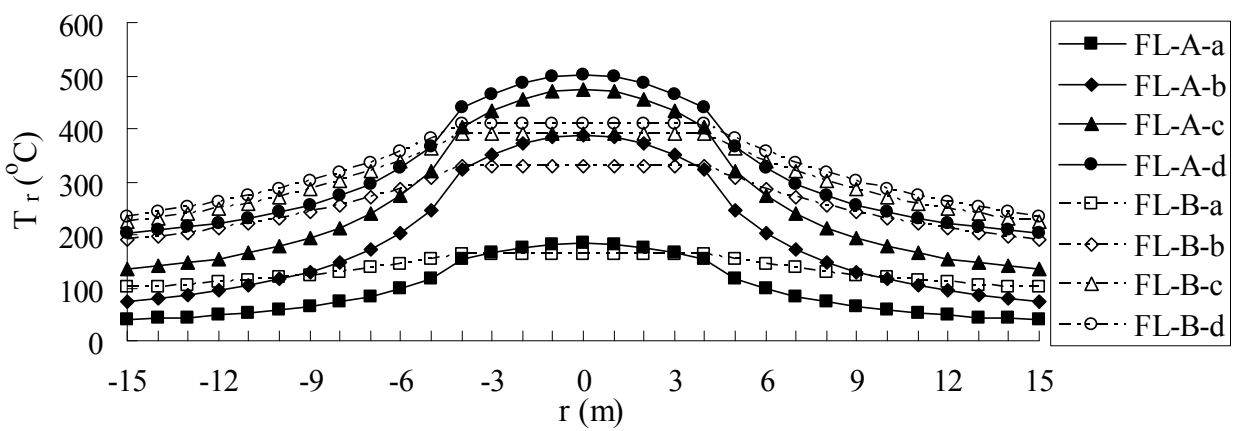

(b) $H=12 \mathrm{~m}, A=6000 \mathrm{~m}^{2}$

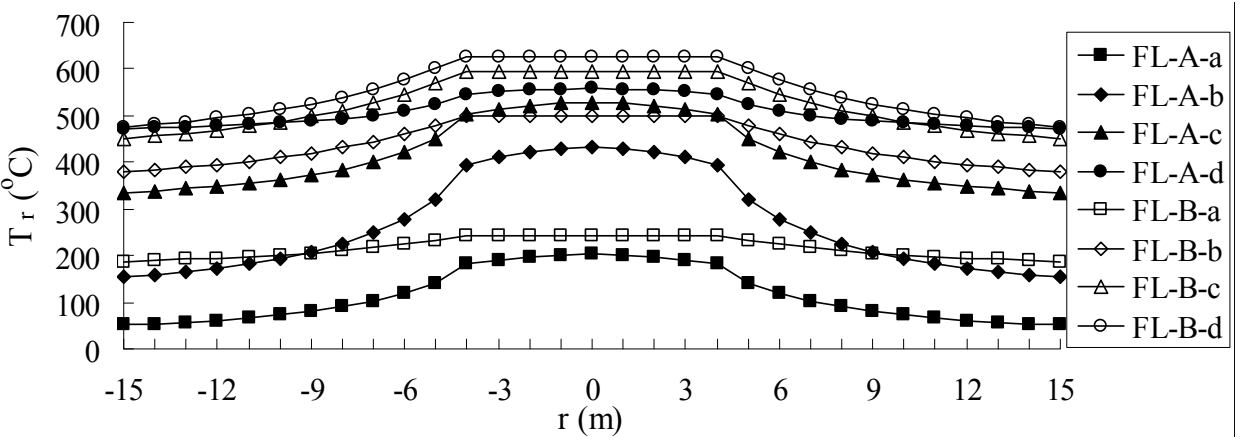

(c) $H=20 \mathrm{~m}, A=500 \mathrm{~m}^{2}$

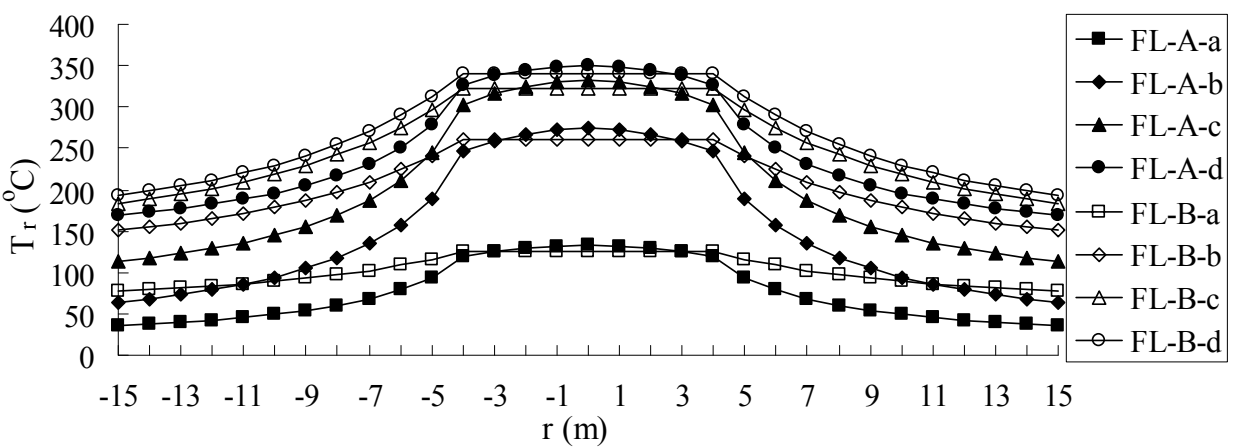

(d) $H=20 \mathrm{~m}, A=6000 \mathrm{~m}^{2}$

Figure 21. Air Temperature Distribution near the Ceiling of Large Space $\left(Q_{\mathrm{c}}=25 \mathrm{MW}\right)$

(FL-A is from Eq. 34, and FL-B is from Eq. 35, a-5min, b-20min, c-60min, d-120min)

Comparing curves in Figures 21 (a) to (d), the differences between the two temperature distribution curves of Eq. 34 and 35 are as follows.

(1) At the beginning phase, there is a large difference between the two curves (see curves FL-A-a and FL-B-a), however after 120 minutes' burning, the two curves become basically consistent with each other (see curves FL-A-d and FL-B-d). 
(2) The air temperature distribution curve above the fire source (in impact area), which can be calculated from Eq. 35, is close to a horizontal line, therefore the temperature is almost the same everywhere (see curves FL-B-a to FL-B-d), and the result disagrees with the actual condition. Furthermore, the larger burning radius is, the greater difference will be. However, the temperature distribution of formula (34) is a curved line, which comparatively obeys the characteristics of the temperature distribution in impact area, and is close to actual condition.

(3) In the temperature distribution curves of formula (35), the horizontal temperature gradient barely changes over time (curves FL-B-a to FL-B-d), which contradicts the phenomenon of time lag in large space fire. However the temperature distribution curves of formula (34) demonstrate a smooth tendency with the increasing of burning time (curves FL-A-a to FL-A-d). Furthermore, as indoor area increases, the effect of time lag becomes even more obvious, as the curve of FL-A-b displays in Figures 21 (a) and (b). Therefore, formula (34) proposed in this paper is more suitable for calculating the air temperature near the ceiling of large space structures in fire, and has a higher accuracy than others.

\subsection{2 $Q_{c}$ and $H$ are constant, changing $A$}

Changing the indoor area $A$, while keeping the heat release rate $Q_{\mathrm{c}}=5 \mathrm{MW}$, and the height of ceiling $H=12 \mathrm{~m}$ unchanged, the air temperature distribution curves calculated from formula (34) and (35) are displayed in Figures 22 (a) and (b) (The temperature distribution curves of Figure 22 correspond to different burning durations--5min, 20min, 60min, and 120min).

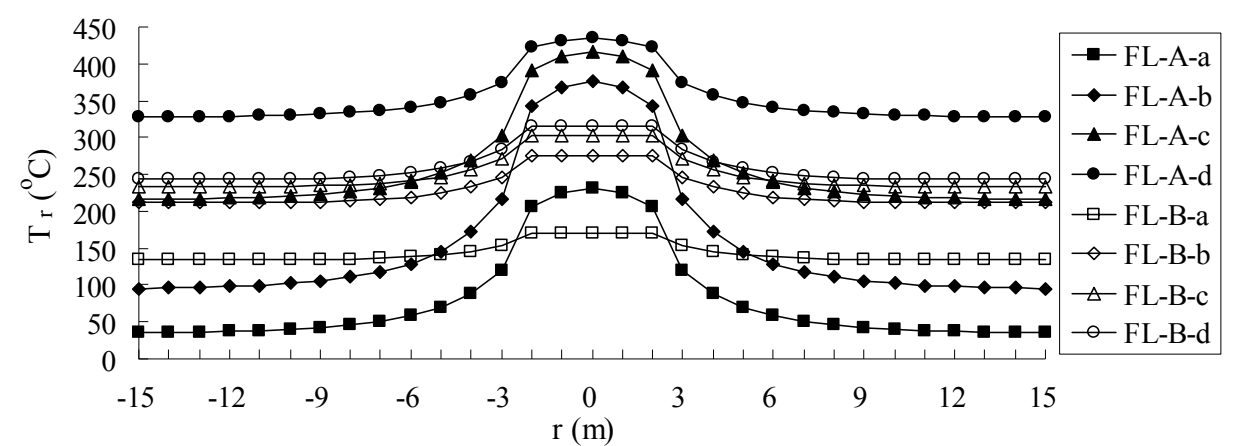

(a) $A=500 \mathrm{~m}^{2}$

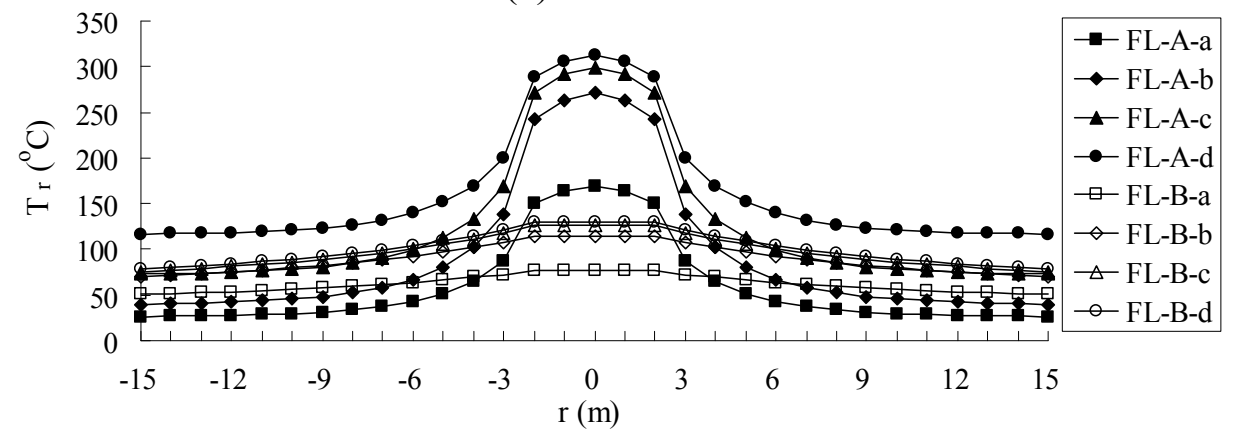

(b) $A=6000 \mathrm{~m}^{2}$

Figure 22. Air Temperature Distribution near the Ceiling of Large Space $\left(Q_{\mathrm{c}}=5 \mathrm{MW}, H=12 \mathrm{~m}\right)$

(FL-A is from Eq. 34, and FL-B from Eq. 35, a-5min, b-20min, c-60min, d-120min)

Comparing the temperature distribution curves in Figures 22 (a) and (b), for small heat release rate $\left(Q_{\mathrm{c}}=5 \mathrm{MW}\right)$, the air temperature above the fire source of formula (34) is significantly higher than that of formula (35). In this sense, with formula (34) proposed in this paper, the local effect of temperature distribution is more obvious, and the relationship between the indoor area and the effect is positive. The reasons are mainly as follows: (1) the smaller the heat release rate, the 
weaker the thrust generated by the smoke plume, which slows down the horizontal diffusion of heat and the mixture of cold and hot air. Therefore the local effect of air temperature is much more obvious; (2) in the derivation process of formula (34), the assumption of energy dissipation is ignored; therefore the result of this formula tends to be conservative.

\subsubsection{Relationship between air temperature along the centreline of ceiling and burning time.}

According to formula (34) and (35), the relationship between air temperature along the centreline of ceiling and burning time can be obtained for different heat release rates, different indoor areas, and different heights of ceiling, as demonstrated in Figures 23 (a) to (d) (The temperature distribution curves of Figure 23 correspond to different heights of ceiling ).

Comparing the curves in Figures 23 (a) to (d), for ceiling height $H<10 \mathrm{~m}$, the air temperature along the centreline of ceiling of Eq. 34 is higher than that of Eq. 35. In addition, the smaller the heat release rate, the larger the difference between the two results, as shown in Figures 23 (c) and (d). When the ceiling height $H$ is less than twice the diameter of fire source, it is difficult to form a steady rising smoke plume, and the assumptions in the derivation process of Eq. 34 will be invalid. Therefore, for ceiling height $H<10 \mathrm{~m}$, there are significant differences between the results of Eq. (34) and (35). However for ceiling height $H \geq 10 \mathrm{~m}$, the results of Eq. 34 and 35 are consistent with each other.

In conclusion, in order to calculate air temperature near the ceiling of large space structures in fire with formula (34) accurately, the application scope of the formula should be: height of ceiling $H \geq 10 \mathrm{~m}$, indoor area $A \geq 500 \mathrm{~m}^{2}$, and heat release rate $Q_{\mathrm{c}} \geq 5 \mathrm{MW}$.



(a) $Q_{\mathrm{c}}=25 \mathrm{MW}, A=500 \mathrm{~m}^{2}$

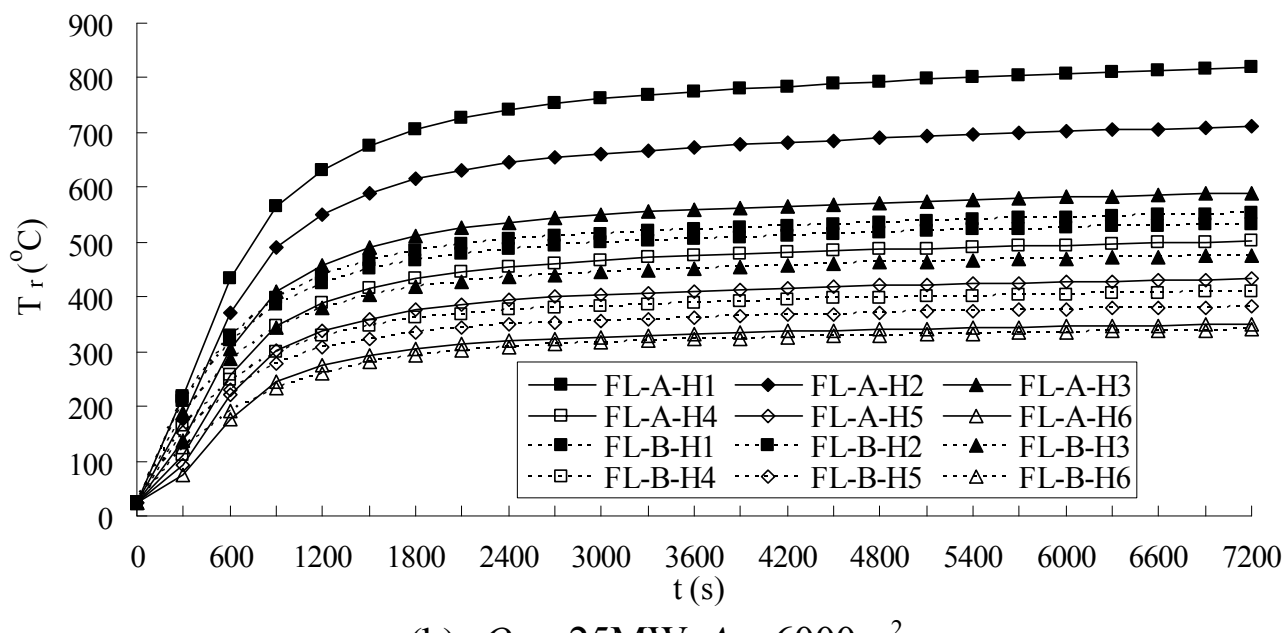

(b) $Q_{\mathrm{c}}=25 \mathrm{MW}, A=6000 \mathrm{~m}^{2}$ 


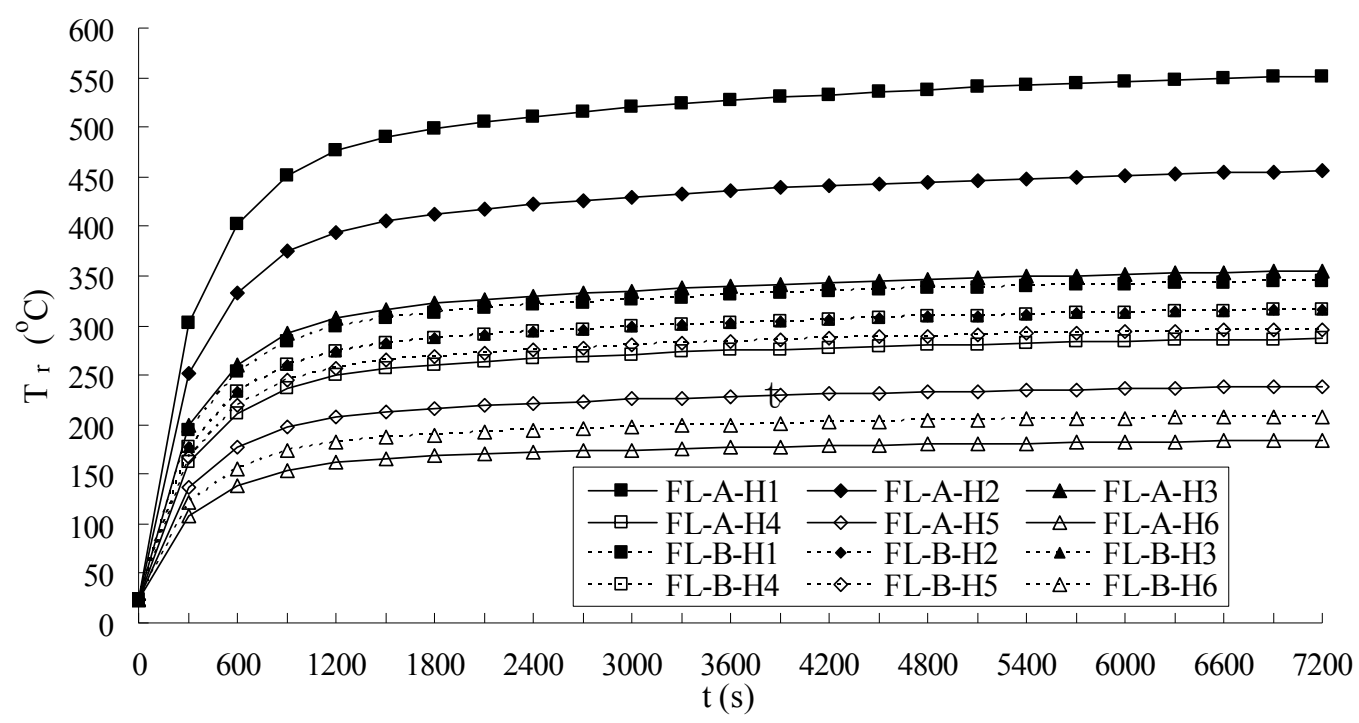

(c) $Q_{\mathrm{c}}=5 \mathrm{MW}, A=500 \mathrm{~m}^{2}$

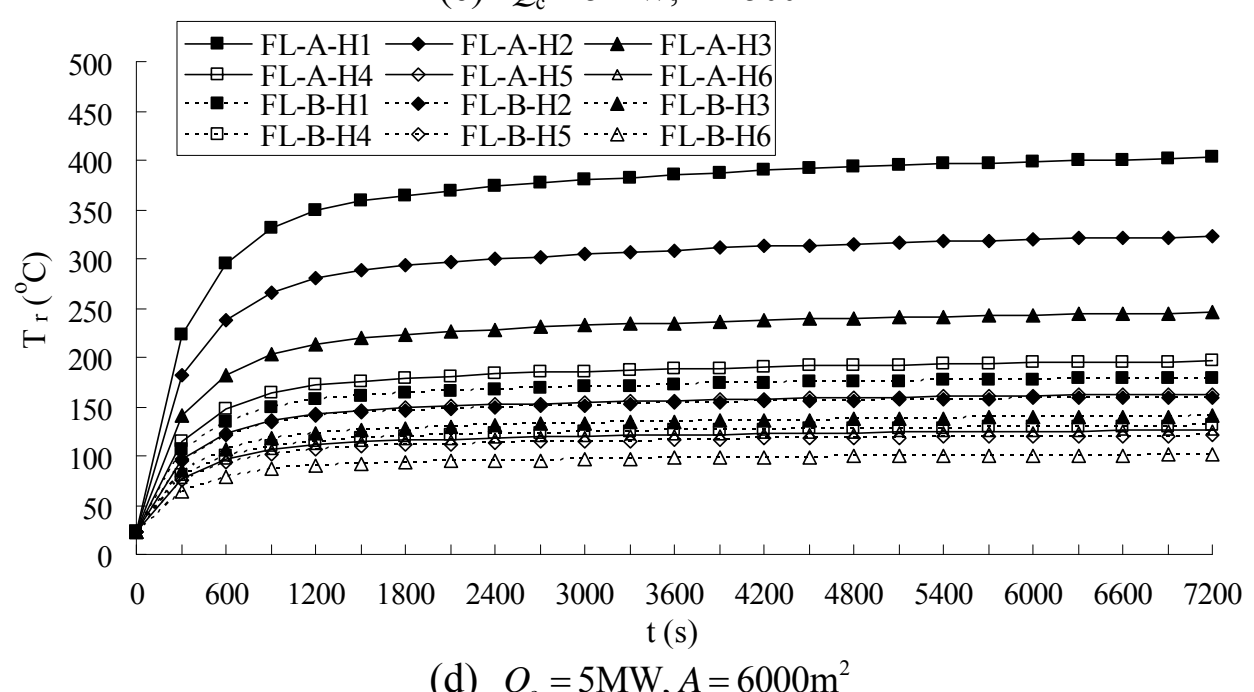

Figure 23. Relationship between Air Temperature along Centreline of Ceiling and Burning time

(FL-A from Eq. 34, FL-B from Eq. 35, H1-4m, H2-6m, H3-9m, H4-12m, H5-15m, H6-20m)

\section{EXAMPLE}

A multi-function hall in a library is an indoor, semi-underground large space structure with a large capacity-- $28 \mathrm{~m}$ long, $30 \mathrm{~m}$ wide, and $10 \mathrm{~m}$ high with a total floor area of $840 \mathrm{~m}^{2}$. The plane layout and the function are displayed in Figure 24. Based on performance-based fire protection analysis and design [31], according to structure type, function, and combustible distribution of the multi-function hall, the combustibles can be classified into two major types (for example, curtain and seat), and different fire scenarios also can be defined. The information regarding type, maximum heat release rate, and fire growth rate in different fire scenarios are given in Table 8 . The locations of different fire sources are demonstrated in Figure 25. 


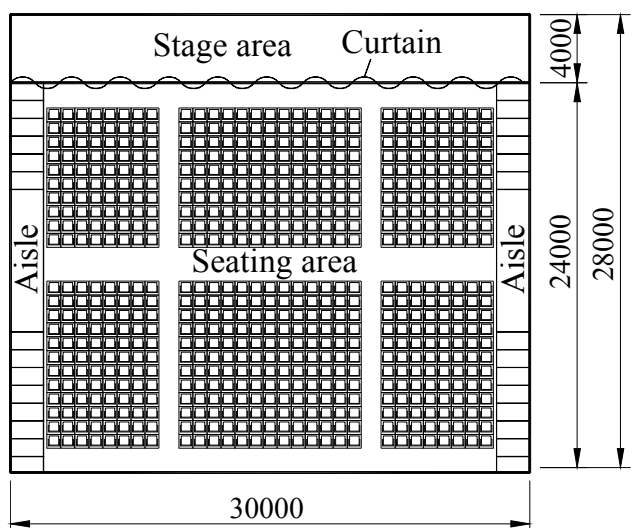

Figure 24. Plane Layout of Multi-function Hall

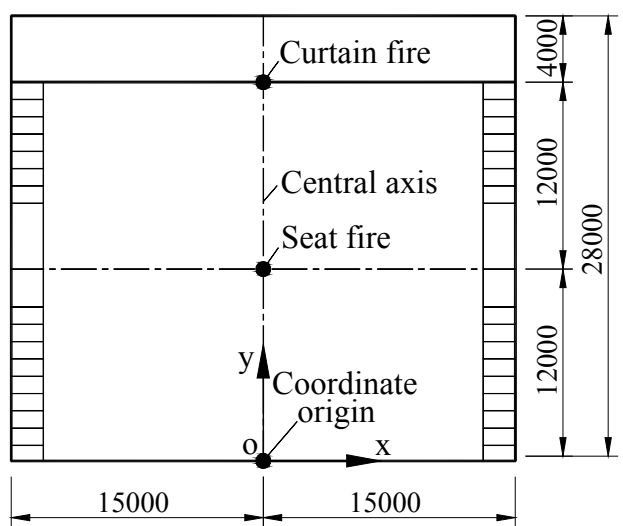

Figure 25. Locations of Fire Sources

With the fire dynamic simulation software CFAST-v4.02 and field simulation software FDS3.0, Ref [31] calculates the ceiling temperature along the centerline (axis y in the Figure 25) at different burning time. Table 9 demonstrates the results for different fire scenarios mentioned.

In the meantime, the air temperatures near the ceiling along the centreline, for fire scenarios FS1 FS4 in Table 8 at different burning time, are calculated with Eq. 34. The results are compared with those in Table 9, as displayed in Figures 26 (a) to (d) (The temperature distribution curves of Figure 26 correspond to different burning time).

Table 8. Information of Different Fire Scenarios

\begin{tabular}{|c|c|c|c|c|c|}
\hline Type & $\begin{array}{c}\text { Fire } \\
\text { scenarios }\end{array}$ & Main material & $\begin{array}{c}\text { Unit heat } \\
\text { release rate }\end{array}$ & $\begin{array}{c}\text { Maximum } \\
\text { heat } \\
\text { release } \\
\text { rate }\end{array}$ & $\begin{array}{c}\text { Fire growth } \\
\text { rate }\end{array}$ \\
\hline \multirow{2}{*}{ Curtain } & FS1 & $\begin{array}{c}\text { Canvas and fibers. } \\
\text { (No fire-retardant } \\
\text { treatment) }\end{array}$ & $\begin{array}{c}88 \sim 127 \\
\mathrm{~kW} / \mathrm{m}^{2}\end{array}$ & $6 \mathrm{MW}$ & Fast \\
\cline { 2 - 6 } & $\mathrm{FS} 2$ & $\begin{array}{c}\text { Canvas and fibers. } \\
\text { (fire-retardant treatment) }\end{array}$ & $\begin{array}{l}88 \sim 127 \\
\mathrm{~kW} / \mathrm{m}^{2}\end{array}$ & $4 \mathrm{MW}$ & Medium \\
\hline \multirow{2}{*}{ Seat } & $\mathrm{FS} 3$ & Sofa sort & $14 \sim 18 \mathrm{MJ} / \mathrm{kg}$ & $16 \mathrm{MW}$ & Fast \\
\cline { 2 - 6 } & $\mathrm{FS} 4$ & Wooden chair sort & $1.8 \sim 7.0 \mathrm{MJ} / \mathrm{kg}$ & $8 \mathrm{MW}$ & Medium \\
\hline
\end{tabular}

Table 9. Air Temperature near the Ceiling along the Axis y for Different Fire Scenarios $\left({ }^{\circ} \mathrm{C}\right)$

\begin{tabular}{|c|c|c|c|c|c|c|c|c|c|c|c|c|c|c|c|c|}
\hline \multirow{2}{*}{$\begin{array}{c}\text { Fire } \\
\text { scenarios }\end{array}$} & \multirow{2}{*}{$\begin{array}{l}\text { Burning } \\
\text { time }\end{array}$} & \multicolumn{15}{|c|}{ Horizontal distance on y axis (m) } \\
\hline & & 0 & 2 & 4 & 6 & 8 & 10 & 12 & 14 & 16 & 18 & 20 & 22 & 24 & 26 & 28 \\
\hline \multirow{4}{*}{ FS1 } & $60 \mathrm{~s}$ & 23.6 & 23.8 & 24.0 & 24.4 & 24.8 & 25.0 & 25.6 & 26.0 & 26.8 & 28.2 & 30.0 & 32.8 & 34.8 & 32.8 & 30.0 \\
\hline & $180 \mathrm{~s}$ & 25.0 & 25.3 & 25.6 & 26.0 & 26.4 & 27.0 & 27.6 & 30.8 & 34.4 & 38.6 & 49.8 & 62.0 & 69.0 & 62.0 & 49.8 \\
\hline & $300 \mathrm{~s}$ & 45.0 & 45.2 & 45.5 & 45.8 & 46.2 & 46.7 & 48.2 & 48.9 & 52.2 & 66.6 & 108 & 160. & 195 & 160 & 108 \\
\hline & $600 \mathrm{~s}$ & 52.0 & 52.5 & 53.0 & 53.8 & 55.0 & 56.0 & 58.0 & 61.2 & 68.2 & 96.2 & 142 & 256 & 345 & 256 & 142 \\
\hline \multirow{4}{*}{ FS2 } & $60 \mathrm{~s}$ & 23.6 & 23.7 & 23.8 & 23.9 & 24.0 & 24.2 & 24.4 & 24.6 & 24.8 & 25.0 & 25.4 & 26.6 & 28.4 & 26.6 & 25.4 \\
\hline & $180 \mathrm{~s}$ & 25.0 & 26.5 & 28.2 & 30.1 & 32.4 & 34.2 & 36.2 & 38.6 & 40.2 & 42.4 & 45.2 & 46.9 & 49.5 & 46.9 & 45.2 \\
\hline & $300 \mathrm{~s}$ & 29.6 & 31.2 & 33.6 & 35.8 & 37.7 & 40.6 & 44.2 & 48.2 & 52.5 & 62.4 & 76.3 & 92.0 & 116 & 92.0 & 76.3 \\
\hline & $600 \mathrm{~s}$ & 45.0 & 46.0 & 47.2 & 48.6 & 50.0 & 53.2 & 55.8 & 59.2 & 62.8 & 82.6 & 123 & 232 & 272 & 232 & 123 \\
\hline \multirow{4}{*}{ FS3 } & $60 \mathrm{~s}$ & 24.1 & 24.8 & 26.5 & 28.2 & 30.5 & 33.2 & 35.0 & 33.2 & 30.5 & 28.2 & 26.5 & 24.8 & 24.1 & 23.8 & 23.5 \\
\hline & $180 \mathrm{~s}$ & 38.2 & 42.7 & 49.2 & 56.8 & 62.5 & 70.4 & 78.0 & 70.4 & 62.5 & 56.8 & 49.2 & 42.7 & 38.2 & 36.9 & 35.0 \\
\hline & $300 \mathrm{~s}$ & 68.2 & 72.2 & 89.4 & 110 & 132 & 154 & 165 & 154 & 132 & 110 & 89.4 & 72.6 & 68.2 & 57.3 & 48.0 \\
\hline & $600 \mathrm{~s}$ & 92.5 & 105 & 136 & 221 & 306 & 436 & 460 & 436 & 306 & 221 & 136 & 105 & 92.5 & 76.8 & 65.1 \\
\hline \multirow{4}{*}{ FS4 } & $60 \mathrm{~s}$ & 23.8 & 24.6 & 25.4 & 26.0 & 27.2 & 28.4 & 29.0 & 28.4 & 27.2 & 26.0 & 25.4 & 24.6 & 23.8 & 23.1 & 22.5 \\
\hline & $180 \mathrm{~s}$ & 32.4 & 33.5 & 36.2 & 38.6 & 44.2 & 50.3 & 56.0 & 50.3 & 44.2 & 38.6 & 36.2 & 33.5 & 32.4 & 31.8 & 31.2 \\
\hline & $300 \mathrm{~s}$ & 46.0 & 48.3 & 52.8 & 64.3 & 78.2 & 92.8 & 100 & 92.8 & 78.2 & 64.3 & 52.8 & 48.3 & 46.0 & 44.8 & 43.4 \\
\hline & $600 \mathrm{~s}$ & 56.0 & 65.8 & 72.6 & 95.1 & 140 & 240 & 265 & 240 & 140 & 95 & 72.6 & 65.8 & 56.0 & 52.3 & 47.5 \\
\hline
\end{tabular}




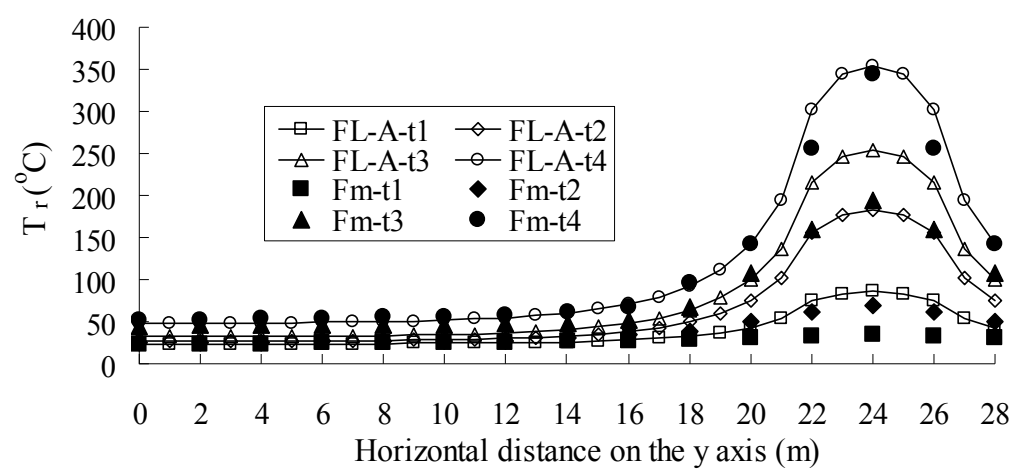

(a) Fire scenario FS1

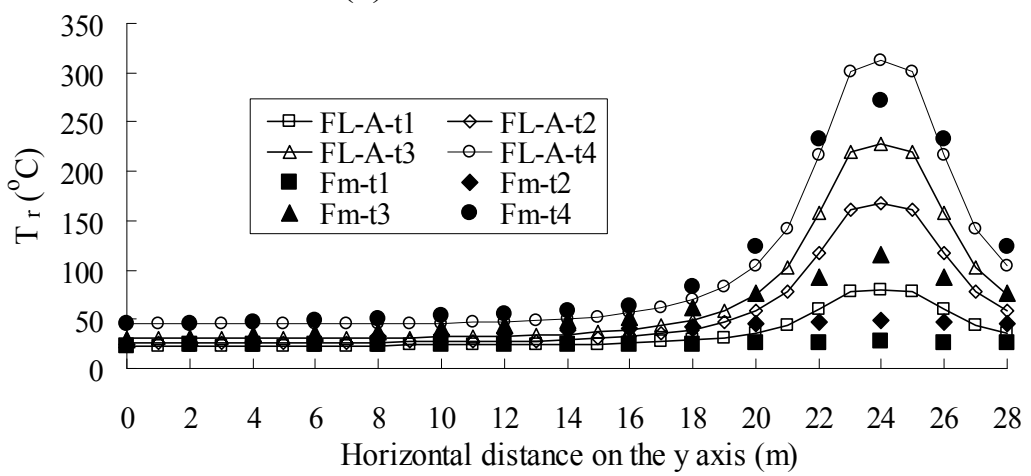

(b) Fire scenario FS2

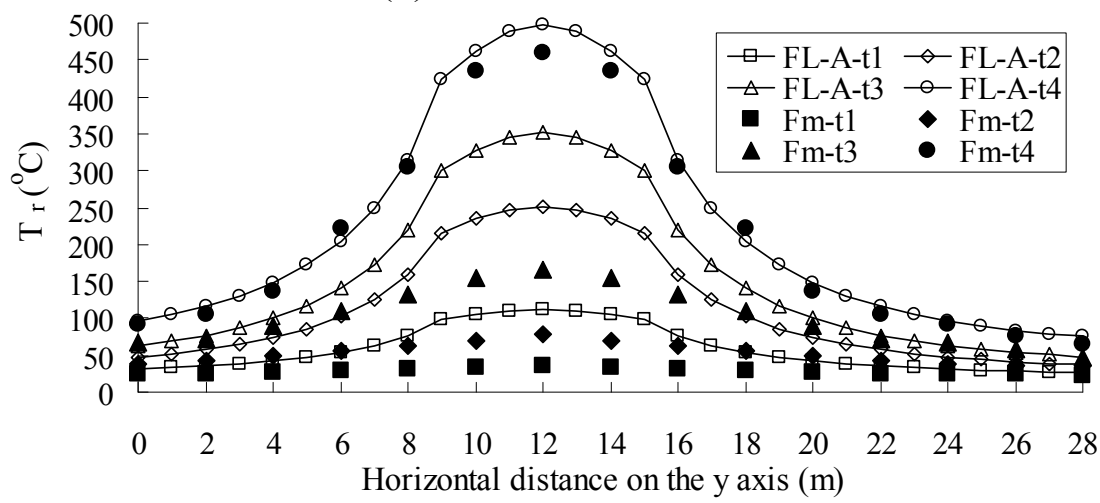

(c) Fire scenario FS3

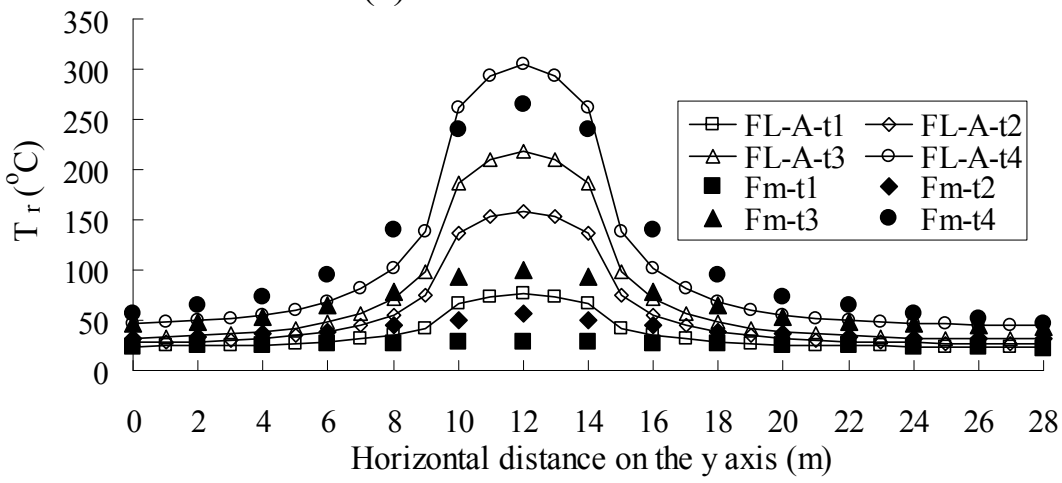

(d)Fire scenario FS4

Figure 26. Comparison of Air Temperature Distributions near the Ceiling along Centreline at Different Fire Scenarios

(FL-A from Eq. 34, Fm is the Values of Table 9, t1-60s, t2-180s, t3-300s, t4-600s) 
As shown in Figures 26 (a) to (d), during the early stage of burning (about the first 300s of burning time), the air temperatures calculated with Eq. 34 are generally higher than those in Table 9. In Figure 26 (a), for example, for burning time 180s, 300s, and 600s, the corresponding temperatures calculated with formula (34) are respectively $183^{\circ} \mathrm{C}, 253^{\circ} \mathrm{C}$, and $3545^{\circ} \mathrm{C}$. Compared with the simulation temperatures in of $69^{\circ} \mathrm{C}, 195^{\circ} \mathrm{C}$, and $345^{\circ} \mathrm{C}$ as in Table 9 , the former are higher by $166 \%, 30 \%$, and $2.8 \%$ respectively. It can be seen that, due to large temperature difference between hot and cold air, the heat dissipation of the smoke plume is significant in the early stage of burning, which is ignored in the derivation of Eq. 34. Therefore there are some differences between the analytical and numerical results. However, if the heat dissipation recedes with burning continuing, the temperatures calculated by Eq. 34 may tend to be close to the simulation ones in Table 9.

\section{CONCLUSION}

Based on the field model of fire thermodynamics and heat transfer, the temperature field model of large space fire is established, which considers fire source, smoke plume, and smoke layer model. Parametric studies of the large space fire were carried out and the results showed that the duration of burning is less than 80 minutes when the total amount of combustibles is not more than $2000 \mathrm{~kg}$. However, if the heat release rate $Q_{\mathrm{c}}$ is less than $5 \mathrm{MW}$, the burning time of fire can be more than 120 minutes. It is thus recommended that the burning duration may be taken as 120 minutes conservatively in the fire analysis of large-space steel structures.

An analytical expression (Equation 34) has been derived which can be used to predict the air temperature of large space fire that meets the criteria of (1) ceiling height greater than $10 \mathrm{~m},(2)$ indoor area more than $500 \mathrm{~m}^{2}$ and (3) heat release rate greater than $5 \mathrm{MW}$. The accuracy of the proposed equation was verified by comparing the results with those obtained by fire dynamic simulation software.

\section{ACKNOWLEDGEMENTS}

The research was supported by a project funded by the Priority Academic Program Development of Jiangsu Higher Education Institutions, Jiangsu Provincial Forward-Looking Cooperation Foundation of Industry, Education and Research (No. BY2012200 and No. BY2009151), and National Natural Science Foundation of China (No. 51378105 and No. 51008065). The authors are grateful to the financial support.

\section{REFERENCES}

[1] Fan, Z., Wang, Z. and Tang, J., "Analysis on Temperature Field and Determination of Temperature upon Healing of Large-span Steel Structure of the National Stadium", Jianzhu Jiegou Xuebao, 2007, Vol. 28, No. 2, pp. 32-40.

[2] Yu, F.B., Wang, X.T., Zhou, M. and Wang, W.Z., "Research on Fire Resistance Performance of Pre-stressed Suspended Steel Reticulated Shell”, Advanced Materials Research, 2011, Vol. 163, No. 1, pp. 790-794.

[3] Li, G.Q. and Du, Y., "Utility Temperature Elevation Empirical Formula in Large Space Fire", Fire Science and Technology, 2005, Vol. 24, No. 5, pp. 283-287.

[4] Xue, H., Ho, J.C., Cheng, Y.M., "Comparison of Different Combustion Models in Enclosure Fire Simulation”, Fire Safety Journal, 2001, Vol. 36, No. 1, pp. 37-54.

[5] Cooper, L.Y., "Smoke Movement in Rooms of Fire Involvement and Adjacent Spaces", Fire 
Safety Journal, 1981, Vol. 3, pp. 201-214.

[6] Venkatasubbaiah, K. and Jaluria, Y., "Numerical Simulation of Enclosure Fires with Horizontal Vents", Numerical Heat Transfer, 2012, Vol. 62, pp.179-196.

[7] Floyd, J.C., McGrattan, K.B., Hostikka, S. and Baum, H.R., "CFD Fire Simulation Using Mixture Fraction Combustion and Finite Volume Radiative Heat Transfer", Journal of Fire Protection Engineering, 2003, Vol. 13, No. 4, pp. 275.

[8] Chow, W.K. and Yin, R., "Discussion on two plume formulae with computational fluid dynamics", Journal of Fire Sciences, 2002, Vol. 20, No. 3, pp. 179-201.

[9] Li, G.Q. and Du, Y., "Analyses the Parameters of Fire Temperature Elevation at the top of Large Space Buildings”, Fire Science and Technology, 2005; Vol. 24, No. 1, pp.19-22.

[10] Huang, L.Y. and Wen, J.X., "Field Modelling of Large Scale Compartment Jet Fires by Constrained Equilibrium Method", Fire Safety Science - Proceedings of the 6th International Symposium, 2000, Vol. 1, pp. 361-372.

[11] Shi, C.L., Zhong, M.H., Fu, T.R. and He, L., “An Investigation on Spill Plume Temperature of Large Space Building Fires", Journal of Loss Prevention in the Process Industries, 2009, Vol. 22, No. 4, pp. 76-85.

[12] Cooper, L.Y. and Stroup, D.W., "Thermal Response of Unconfined Ceilings above Growing Fires and the Importance of Convective Heat Transfer", Journal of Heat Transfer, 1987, Vol. 109, No. 1, pp. 172-178.

[13] Cooper, L.Y., "Heat Transfer in Compartment Fires near Regions of Ceiling Jet-wall Impingement", American Society of Mechanical Engineers, Heat Transfer Division, 1987, Vol. 73, pp. 57-62.

[14] Harmathy, T.Z., "Fire Safe Design and Concrete", Longman Scientific \& Technical, London, 1993, Vol. 1, pp. 210-211.

[15] Anon., "Design Guide: Structural Fire Safety-workshop (CIB W14)", Fire Safety Journal, 1986, Vol. 10, No. 2, pp. 75-137.

[16] Vrouwenvelder, T., "JCSS Probabilistic Model Code", Structural Safety, 1997, Vol.19, No.3, pp. 245-251.

[17] Sunil, K. and Kameswara, R.C., "Fire Loads in Office Building", Journal of Structural Engineering, 1997, Vol. 123, No. 3, pp. 365-368.

[18] Harmathy, T.Z. and Mehaffey, J.R., "Design of Buildings for Prescribed Levels of Structural Fire Safety", ASTM Special Technical Publication, 1985, Vol. 1, pp. 160-175.

[19] She, G.J., "The Fire Emulation and Resistance of Long-span Spatial Steel Structure Based on Performance", Master dissertation, Southeast University, Nanjing, 2007.

[20] European Committee for Standardization (CEN), "Eurocode 1-Actions on Structures, Part 1-2: General Actions-Actions on Structures Exposed to Fire”, CEN, Brussels, 2003.

[21] Chow, W.K., Yi, L. and Shi, C.L., "Experimental Studies on Mechanical Smoke Exhaust System in an Atrium", Journal of Fire Sciences, 2005, Vol. 23, No. 5, pp. 429-444.

[22] William, D. D., "Comparison of Algorithms to Calculate Plume Centerline Temperature and Ceiling Jet Temperature with Experiments", Journal of Fire Protection Engineering, 2002, Vol.12, pp.9-29.

[23] Motevalli, V., "Numerical Prediction of Ceiling Jet Temperature Profiles during Ceiling Heating Using Empirical Velocity Profiles and Turbulent Continuity and Energy Equations", Fire Safety Journal, 1994, Vol. 22, No. 2, pp. 125-144.

[24] Zukoski, E.E., Kubota, T. and Cetegen, B., "Entrainment in Fire Plumes", Fire Safety Journal, 1980, Vol. 3, No.3, pp. 107-121.

[25] Gershuni, G.Y., Zhukhovitskiy, Y.M. and Yurkov, Y.S., "Vibrational Thermal Convection in a Horizontal Layer with Internal Heat Sources", Heat Transfer - Soviet Research, 1991, Vol. 23, No. 4, pp. 959-967.

[26] Guan, D., "Calculation of Unsteady Aerodynamic", Beijing Aeronautics and Astronautics Press, 1991. 
[27] Fang, J., Shu, X.M., Yuang, H.Y. and Zhen, X., "Self-preserving Size Distribution of Fire Soot Fractal Coagulation in Flaming Combustion", Journal of Fire Sciences, 2004, Vol. 22, No. 1, pp. 53-68.

[28] Beltaos, S. and Rajaratnam, N., "Impinging Circular Turbulent Jets", ASCE J Hydraulics Div, 1974, Vol. 100, No. 10, pp. 1313-1328.

[29] Bai, Y., Shi, Y.J. and Wang, Y.Q., "Numerical Simulation Analysis on Temperature Field for Large-Space Structures under Fire”, China Safety Science Journal, 2006, Vol. 16, No. 1, pp. 34-38.

[30] Jin, X.H., Huo, R. and Li, Y.Z., "Study on Dynamic Display of Smoke Movement in Atrium Fire”, China Safety Science Journal, 1999, Vol. 4, No. 9, pp. 26-10.

[31] Research Report, "Fire Safety Evaluation Report of New Library Multi-Function Room of Nanjing”, State Key Laboratory of Fire Science of University of Science and Technology of China, 2003. 